\title{
Airborne Spectral Measurements of Ocean Directional Reflectance
}

\author{
Charles K. Gatebe, ', ${ }^{2}$ Michael D. King, Alexei I. Lyapustin, ${ }^{1,2}$ \\ G. THOMAS ARNOLD, ${ }^{3}$ AND JENS REDEMANN
}

\section{Popular Summary}

During summer of 2001 NASA's Cloud Absorption Radiometer (CAR) obtained measurement of ocean angular distribution of reflected radiation or BRDF (bidirectional reflectance distribution function) aboard the University of Washington Convair CV-580 research aircraft under cloud-free conditions. The measurements took place over the Atlantic Ocean off the eastern seaboard of the U.S. in the vicinity of the Chesapeake Light Tower and at nearby National Oceanic and Atmospheric Administration (NOAA) Buoy Stations. The measurements were in support of CLAMS, Chesapeake Lighthouse and Aircraft Measurements for Satellites, field campaign that was primarily designed to validate and improve NASA's Earth Observing System (EOS) satellite data products being derived from three sensors: MODIS (MODerate Resolution Imaging Spectro-Radiometer), MISR (Multi-angle Imaging Spectro-Radiometer) and CERES (Clouds and Earth's Radiant Energy System). Because of the high resolution of the CAR measurements and its high sensitivity to detect weak ocean signals against a noisy background, results of radiance field above the ocean are seen in unprecedented detail. The study also attempts to validate the widely used Cox-Munk model for predicting reflectance from a rough ocean surface.

Goddard Earth Sciences and Technology Center, University of Maryland, Baltimore County, Baltimore, Maryland

NASA Goddard Space Flight Center, Greenbelt, Maryland

L-3 Communications Government Services, Inc., Vienna, Virginia

Bay Area Environmental Research Institute, Sonoma, California 


\title{
Airborne Spectral Measurements of Ocean Directional Reflectance
}

\author{
Charles K. Gatebe, ${ }^{1,2}$ Michael D. King, ${ }^{2}$ AleXei I. Lyapustin, ${ }^{1,2}$ \\ G. THOMAS ARNOLD, ${ }^{3,2}$ AND JENS REDEMANN ${ }^{4}$
}

Short title: Remote Sensing of Ocean Reflectance during CLAMS

Journal of the Atmospheric Sciences

(Manuscript submitted January 7, 2004)

${ }^{1}$ Goddard Earth Sciences and Technology Center, University of Maryland, Baltimore County, Baltimore, Maryland

2 NASA Goddard Space Flight Center, Greenbelt, Maryland

3 L-3 Communications Government Services, Inc., Vienna, Virginia

4 Bay Area Environmental Research Institute, Sonoma, California 
Authors:

Dr. Charles K. Gatebe

Goddard Earth Sciences and Technology Center

University of Maryland Baltimore County

Baltimore, MD 21228-5398 USA

(gatebe@climate.gsfc.nasa.gov)

Dr. Michael D. King

Earth Sciences Directorate

NASA Goddard Space Flight Center

Greenbelt, MD 20771 USA

(michael.d.king@nasa.gov)

Dr. Alexei I. Lyapustin

Goddard Earth Sciences and Technology Center

University of Maryland Baltimore County

Baltimore, MD 21228-5398 USA

(alyapust@pop900.gsfc.nasa.gov)

Mr. G. Thomas Arnold

L-3 Communications Government Services, Inc.

Vienna, VA 22180 USA

(arnold@climate.gsfc.nasa.gov)

Dr. Jens Redemann

Bay Area Environmental Research Institute,

$5603^{\text {rd }}$ Street West

Sonoma, CA 95476

jredemann@mail.arc.nasa.gov) 


\begin{abstract}
The Cloud Absorption Radiometer (CAR) was flown aboard the University of Washington Convair CV-580 research aircraft during the CLAMS field campaign and obtained measurements of bidirectional reflectance distribution function (BRDF) of the ocean in July and August 2001 under different illumination conditions with solar zenith angles ranging from $15^{\circ}-46^{\circ}$. The BRDF measurements were accompanied by concurrent measurements of atmospheric aerosol optical thickness and column water vapor above the airplane. The method of spherical harmonics with Cox-Munk wave-slope distribution is used in a new algorithm developed for this study to solve the atmosphere-ocean radiative transfer problem, and remove the effects of the atmosphere from airborne measurements. The algorithm retrieves simultaneously the wind speed and full ocean BRDF (sunglint and water-leaving radiance) from CAR measurements, and evaluates total albedo and equivalent albedo for the water-leaving radiance outside the glitter. Results show good overall agreement with other measurements and theoretical simulations, with the anisotropy of the water-leaving radiance clearly seen. However, the water-leaving radiance does not show a strong dependence on solar zenith angle as suggested by theoretical studies. The spectral albedo was found to vary from $4.1-5.1 \%$ at $\lambda=0.472 \mu \mathrm{m}$ to $2.4-3.5 \%$ for $\lambda \geq 0.682$ $\mu \mathrm{m}$. The equivalent water-leaving albedo ranges from $1-2.4 \%$ at $\lambda=0.472 \mu \mathrm{m}$ to $0.1-0.6 \%$ for $\lambda \geq 0.682 \mu \mathrm{m}$ and 0.1 to $0.3 \%$ for $\lambda=0.870 \mu \mathrm{m}$. Results of the validation of the Cox-Munk model under the conditions we measured show that although the model reproduces the shape of sunglint with an accuracy of better than $30 \%$, it underestimates the center of the glint reflectance by about $30 \%$ for low wind speeds $\left(<2-3 \mathrm{~ms}^{-1}\right)$. In cases of high wind speed, the model with GramCharlier expansion seems to provide the best fit.
\end{abstract}




\section{Introduction}

In this study we discuss ocean surface anisotropy obtained with NASA's Cloud Absorption Radiometer (CAR) aboard the University of Washington Convair CV-580 research aircraft for different illumination conditions under clear sky. The measurements were obtained over the Atlantic Ocean off the eastern seaboard of the U.S. in the vicinity of the Chesapeake Light Tower and at nearby National Oceanic and Atmospheric Administration (NOAA) Buoy Stations (Fig. 1). Our study was part of the Chesapeake Lighthouse and Aircraft Measurements for Satellites (CLAMS) field experiment that took place between 10 July and 2 August 2001.

The ocean radiance field beneath the surface is generally not isotropic. This has been shown in simulation studies of radiation transport within the oceanatmosphere system using Monte Carlo methods (Morel and Gentili 1993, 1996; Morel et al. 1995). This anisotropy results from the anisotropic optical properties of the water body (namely, its volume scattering function) combined with the illumination conditions that prevail above the surface (Morel and Gentili 1993). Results from field measurements of upwelling radiance distribution at several wavelengths using a submersible camera system confirm the anisotropic nature of the ocean radiance field just beneath the water surface (Morel et al. 1995). However, there seem to be only a few reported measurements, especially at an aircraft altitude, to validate the bidirectional structure of the radiance field leaving the ocean surface over a given scene. We are only aware of the study by Soulen et al. (1999), which discusses spectral bidirectional reflectance distribution functions (BRDF) of the ocean-atmosphere system from measurements obtained over the Atlantic Ocean and Persian Gulf from an aircraft. This study, however, missed the details of the bidirectional structure of the radiance field just above 
the ocean surface because of a lack of atmospheric correction. The anisotropy of the radiance field just above the ocean surface has practical consequences for the interpretation of the ocean signal detected remotely either by aircraft or satelliteborne radiometers, and affects retrieved products such as ocean color and aerosols. For example, a theoretical study by Yang and Gordon (1997) shows that the error in water-leaving radiance caused by assuming the upwelling radiance beneath the ocean surface to be reflected uniformly in all directions is significant in comparison to other errors expected in the water-leaving radiance. This effect is realized mainly for low concentrations of phytoplankton and in the blue region of the electromagnetic spectrum. The assumption of a uniform distribution of water-leaving radiance, as reported by Yang and Gordon (1997), leads to an error of up to $4 \%(\lambda=0.443 \& 0.555 \mu \mathrm{m})$ for observation angles $0^{\circ} \leq \theta \leq 60^{\circ}$ and $0^{\circ} \leq \phi \leq$ $180^{\circ}$, and aerosol optical thicknesses $\tau_{\mathrm{a}}(\lambda) \leq 0.2$ for a range of solar zenith angles $40^{\circ} \leq \theta_{0} \leq 60^{\circ}$. Likewise, Zhao and Nakajima (1997) report errors in simultaneously retrieved water-leaving reflectance and aerosol optical thickness in the range of $10 \%$. Better characterization of anisotropy of the water-leaving radiance field just above the ocean surface would certainly lead to smaller errors in the retrieved ocean biophysical products.

The sun glitter pattern is perhaps one of the most studied optical features of the ocean (e.g., Hulburt 1934; Duntley 1954; Cox and Munk 1954a,b; Schooley 1954; Guinn et al. 1979; Preisendorfer and Mobley 1986). These studies have increased our knowledge not only of sun glitter morphology, but also of the distribution of slopes and curvature at various wind speeds; parameters that are important in the reflection and refraction of acoustics and electromagnetic radiation. Although some satellite borne sensors, e.g., Sea-viewing Wide Field-ofview Sensor (SeaWiFS), avoid sun glitter-partly because no useful retrievals 
were envisaged during its design, and partly due to detector saturation problems-the sun glitter reflectance has been exploited in the retrieval of aerosol absorption (Kaufman et al. 2000) and precipitable water-vapor in the near-infrared (Kleidman et al. 2000). The sun glitter observation and the detection of a small signal of the water-leaving radiances in directions away from the glitter, however, require a sensor with a stable response over a wide dynamical range.

In this study we discuss the anisotropy of the radiance field above the ocean surface from airborne measurements obtained over the Atlantic Ocean with NASA's Cloud Absorption Radiometer (CAR). In order to isolate the reflectance properties of the ocean surface in the absence of the atmosphere, we have developed a rigorous atmospheric correction algorithm for the CAR measurements based on the method of spherical harmonics (Lyapustin and Muldashev 1999, 2000). The algorithm models the water surface reflectance by the Cox-Munk azimuthally independent model, and assumes the water-leaving radiance to be Lambertian. The algorithm retrieves the wind speed from the sun's glitter pattern and evaluates the equivalent albedo for the water-leaving radiance outside the glitter in the CAR spectral bands. Also contained in this study is an attempt to validate under the conditions we measured the widely used Cox-Munk model for predicting surface slope statistics as a function of wind speed.

The remainder of this paper is divided into four sections. Section 2 , on measurements and methods, describes the main characteristics of the instrument, radiometric calibration, and BRDF measurement methodology. Section 3 discusses the method used to retrieve the BRDF. Section 4 presents our results of ocean BRDF and other derived parameters like the total albedo and the equivalent water-leaving albedo. Results of validation of Cox-Munk model under the conditions we measured are discussed in this section. Section 5 concludes with a 
summary of the study.

\section{Measurement Methods}

a. Description of the instrument

In the past we described in depth the Cloud Absorption Radiometer (King et al. 1986; Gatebe et al. 2003). In this study we only highlight some of the important characteristics of the instrument as summarized in Table $1 \& 2$.

The CAR is an airborne multiwavelength scanning radiometer that measures scattered light in fourteen spectral bands between 0.34 and $2.30 \mu \mathrm{m}$ (Table 1). In the normal mode of operation data are sampled simultaneously and continuously on nine individual detectors. Eight of the data channels for spectral bands from $0.34-1.27 \mu \mathrm{m}$ are always registered during the operation, while the ninth data channel is registered for signal selected among six spectral channels (1.55$2.30 \mu \mathrm{m})$ on a filter wheel. The filter wheel can either cycle through all six spectral bands at a prescribed interval (usually changing filter every fifth scan line), or lock onto any one of the six spectral bands, mostly 1.656, 2.103 or $2.205 \mu \mathrm{m}$ and sample it continuously. The CAR scan mirror rotates $360^{\circ}$ in a plane perpendicular to the direction of flight and the data are collected through a $190^{\circ}$ aperture that allows observations of the earth-atmosphere scene around the starboard horizon from local zenith to nadir. In this study we only report results of data analysis from channels between 0.472 and $1.219 \mu \mathrm{m}$. The UV bands were not analyzed because of significant contribution of polarization, which is not taken into account in our algorithm. We also did not process measurements at $1.273 \mu \mathrm{m}$ because the detected signal was systematically lower by $10-20 \%$ than theoretically predicted, the discrepancy of which has not been identified. The filter wheel channels, on the other hand, were not consistently stable during 
measurements and therefore are excluded from our analysis.

Table 2 provides the signal to noise ratio (SNR) in our measurements of BRDF. We chose dark uniform scenes to compute the SNR. An average signal was determined from each scene, and then divided by the standard deviation of the dark-current which was acquired for each data cycle when the detectors were all completely darkened. The radiometric performance of the CAR compares well with Moderate Resolution Imaging Spectroradiometer (MODIS), Multiangle Imaging Spectroradiometer (MISR), SeaWiFS and Coastal Zone Color Scanner (CZCS). In Table 1 of Gordon (1997), the noise equivalent reflectance value at $0.490 \mu \mathrm{m}$ for MODIS is $1.4 \times 10^{-4}$, SeaWiFS is $3.4 \times 10^{-4}$, and CAR values are between $2.0 \times 10^{-5}$ and $6.0 \times 10^{-5}$ at $0.472 \mu \mathrm{m}$. The noise equivalent reflectance value at $0.670 \mu \mathrm{m}$ for MODIS is $4.0 \times 10^{-5}$, SeaWiFS is $2.3 \times 10^{-4}$, MISR is $1.7 \times 10^{-4}, \mathrm{CZCS}$ is $5.1 \times 10^{-4}$, and CAR ranges between $5.0 \times 10^{-5}$ and $1.4 \times 10^{-4}$ at $0.682 \mu \mathrm{m}$. This comparison clearly shows that the sensitivity of CAR, especially at $0.47,0.68$ and 0.87 $\mu \mathrm{m}$, satisfies the accuracy requirements for low water-leaving radiances. On the other hand, relatively low $\mathrm{SNR} \approx 20$ at 1.036 and $1.219 \mu \mathrm{m}$, although sufficient for analysis of the sunglint, may not be adequate for water-leaving reflectance retrievals.

\section{b. Calibration of the CAR}

Radiometric calibration was performed at Goddard Space Flight Center (GSFC) prior to and just after the CLAMS field experiment, at intervals of about two months. In order to determine a suitable calibration for a given flight during the experimental campaign, we assumed a linear change between pre- and postflight calibration and as a function of only the number of flights flown during CLAMS. In this case, there were a total of 12 flights flown, 2 during the instru- 
ment flight test, and 10 during the field experiment. We note that the calibration ratios post-flight/pre-flight averaged about 0.98 for $0.472 \leq \lambda \leq 1.219 \mu \mathrm{m}$. We used the spectral calibration of the CAR that defined the bandpass functions and central wavelengths conducted one year before the CLAMS experiment, assuming that the CAR filter density functions remained stable based on our past experience (Gatebe et al. 2003).

\section{c. Measurements of $B R D F$}

To measure the BRDF of the surface-atmosphere system, the airplane flew in a circle about $3 \mathrm{~km}$ in diameter above the surface, taking roughly 2-3 minutes to complete an orbit (see Fig. 2). For the instrument to image from zenith to nadir, it was dynamically adjusted by a motion control system installed for the CLAMS experiment to compensate for aircraft roll. In the past the airplane had to bank at an angle of $20^{\circ}$ from the vertical with the instrument locked into an imaging mode that was set to allow CAR to image from zenith to nadir. The new method was found to produce better results and reduced tremendously the postprocessing analysis. The CLAMS measurements over the ocean were generally obtained at an altitude of $\sim 200 \mathrm{~m}$ above the surface and under clear sky conditions. From an altitude of $200 \mathrm{~m}$ the pixel resolution is about $4 \mathrm{~m}$ at nadir and about $116 \mathrm{~m}$ at $80^{\circ}$ viewing angle, assuming a $1^{\circ}$ instantaneous field of view of the CAR. Multiple circular orbits were acquired over a selected surface so that average BRDFs smooth out small-scale surface and atmospheric inhomogeneities. With this configuration, the CAR collects between 76400 and 114600 directional measurements of radiance per channel per complete orbit.

We believe using the CAR in this manner is the most mobile and efficient way of measuring a complete surface BRDF, but it is still necessary to correct for 
atmospheric scattering effects both above and below the aircraft in order to isolate the reflectance properties of the underlying surface.

\section{Retrieval of BRDF from measurements}

Figure 2 shows a schematic representation of the instant sea radiance received by the CAR aboard the aircraft, as it scans the surface from a height of 200 $m$ as the airplane orbits a particular scene over the Ocean. The total instant sea radiance received by the CAR may be broken down into four components: (i) $I_{\text {sun }}$ - radiance from the direct solar beam reflected by the ocean surface into the CAR's instantaneous field of view, (ii) $I_{\text {sky }}$ - radiance from scattered photons in the atmosphere that are reflected by the ocean surface to the CAR, (iii) $I_{\text {path }}$ - a part of the radiance along the path from the footprint to the CAR scattered by air molecules and aerosols, and (iv) $I_{\text {water }}$ - water-leaving radiance. Note that the footprint of a single pixel in an ocean image taken by the CAR, typically about 4 meters on a side, assuming $200 \mathrm{~m}$ altitude and IFOV of $1^{\circ}$, is represented by the square box.

The actual three-dimensional situation for a single facet is shown in Fig. 2 (inset). The coordinate system used is such that the origin is the point of reflection with the $X$ axis pointing upwind, the $Z$ axis pointing towards the zenith, and the $Y$ axis pointing crosswind such that a right-handed system is formed. The $X$ $Y$ plane is parallel to the mean sea level and horizontal at the point of reflection. The tilted facet passes through the origin. The facet slopes $Z_{x}$ and $Z_{y}$ in the $X$ and $Y$ directions are given by the slope of the line formed by the intersection of the facet with the $X-Z$ and $Y-Z$ planes, respectively. The two unit vectors $U_{\mathrm{s}}$ and $U_{r}$ point from the origin to the source, and from the origin to the CAR, respectively. The normal to the facet at the origin, $U_{n}$, has been left out of the figure for 
clarity. Each unit vector is specified by its zenith angle $\theta$ and its azimuth angle $\phi$. In general, the three vectors may point in arbitrary directions and are connected by the law of reflection for specular reflection in the form: $U_{\mathrm{s}}+U_{\mathrm{r}}=2 \cos \omega U_{\mathrm{n}}$ where $\omega$ is the angle of incidence and angle of reflection.

In this study we developed a new algorithm for atmospheric correction of CAR measurements to retrieve surface BRDF from the above four components. The method of spherical harmonics with Cox-Munk wave-slope distribution (Cox and Munk 1954a,b) is used here to solve the atmosphere-ocean problem. The basic method is described in several studies (e.g., Lyapustin and Muldashev 1999, 2000). The numerical implementation of this method is named here as SHARM. We provide below an overview of the method in the context of the new algorithm.

\section{a. Algorithm description}

We use the lower boundary condition of the equation of radiative transfer for ocean-atmosphere system to find the reflected radiance $I\left(H ; \mu_{\mathrm{r}}, \phi_{\mathrm{r}}\right)$ in the directions $\left(\mu_{\mathrm{r}}, \phi_{\mathrm{r}}\right)$ for the specified BRDF $R\left(\mu^{\prime}, \mu_{\mathrm{r}}, \phi_{\mathrm{r}}-\phi^{\prime}\right)$ written in the form:

$$
I\left(\mu_{r}, \phi_{r}\right)=F_{0} e^{-\frac{\tau}{\mu_{0}}} \mu_{0} R\left(\mu_{0}, \mu_{r}, \phi_{r}-\phi_{0}\right)+\frac{1}{\pi} \int_{0}^{2 \pi} d \phi \int_{0} I\left(\mu^{\prime}, \mu_{r}, \phi\right) \mu^{\prime} R\left(\mu^{\prime}, \mu_{r}, \phi_{r}-\phi\right) d \mu^{\prime}(1)
$$

Here, $F_{0}$ is the extraterrestrial solar spectral irradiance; $\tau_{\lambda}$ is the atmospheric optical thickness, $\mu_{\mathrm{r}}=\cos \theta_{\mathrm{r}}$ and $\mu_{0}=\cos \theta_{0}$ and $\phi$ denote azimuthal directions as described above. In our notations, $\mu<0$ for the upward directions, and $\mu>0$ otherwise. $R=R_{\mathrm{CM}}+R_{\mathrm{W}}$ is the total bidirectional reflectance distribution function (BRDF) of the ocean. It consists of reflectance of the water surface $R_{C M}$, and of the bulk of water and foam $R_{W}$. In this study we used the Nakajima and Tanaka (1983) version of the azimuthally independent Cox-Munk model (Cox and 
Munk 1954a,b) for the reflectance of the wind-ruffled ocean surface:

$$
R_{C M}\left(\mu^{\prime}, \mu_{r}, \phi_{r}-\phi\right)=\frac{\pi}{\mu^{\prime}} \frac{1}{4 \mu_{r} \mu_{n}} R_{F r}(\omega) P\left(\mu_{n}\right) S\left(\mu^{\prime}, \mu_{r}\right)
$$

where $R_{\mathrm{Fr}}(\omega)$ is the Fresnel reflectance in terms of reflection angle (cf. Fig. 2, inset), $P\left(\mu_{\mathrm{n}}\right)$ is the probability density function of slope distribution with $n$ referring to the orientation of the normal to the wave facet with respect to the $z$-axis, and $S\left(\mu^{\prime}, \mu_{\mathrm{r}}\right)$ the bidirectional shadowing factor defining the conditional probability of occurrence of an event that the wave facet with surface normal contributes to the reflection of light. The functions $P\left(\mu_{\mathrm{n}}\right)$ and $S\left(\mu^{\prime}, \mu_{\mathrm{r}}\right)$ depend on the mean square slope, which linearly grows with the wind speed $u$ as $\sigma^{2}=0.00534 u$. Note that $u\left(\mathrm{~ms}^{-1}\right)$ is measured 10 meters above the water surface. The Fresnel reflection coefficients were calculated based on refractive indices of water taken from Hale and Querry (1973).

We write the solution of the radiative transfer equation at the flight level $\mathrm{z}$ in the following form, separating the direct surface reflected term:

$$
I\left(z ; \mu_{r}, \phi_{r}\right)=F_{0} \mu_{0} R\left(\mu_{0}, \mu_{r}, \Delta \phi_{0}\right) e^{-\frac{\tau_{0}}{\mu_{0}} e^{-\frac{\tau_{0}-\tau(z)}{\left|\mu_{r}\right|}}}+I_{s k y}(z ; R)+I_{\text {path }}(z)
$$

where $I_{\text {sky }}(z ; R)$ is the diffuse (atmospherically scattered) radiance at altitude $z$ that has undergone interactions with the ocean. We have assumed that the water-leaving reflectance does not depend on the angle of incidence. This approximation is only used to calculate the diffuse upwelling radiance $I_{\text {sky }}(z ; R)$ while the direct reflected component (and BRDF) is found explicitly from measurements, retaining the directional features of the water-leaving radiance. This approach mitigates possible error in the BRDF retrieval while keeping high efficacy of the algorithm. On the other hand, it can introduce a small offset that is variable with 
$\theta_{0}$ to the diffuse water-leaving BRDF retrieved from the direct term. To perform atmospheric correction of CAR BRDF measurements, (3) is rewritten in the form:

$$
R\left(\mu_{0}, \mu_{r}, \Delta \phi_{0}\right)=\left\{I_{C A R}\left(\mu_{r}, \Delta \phi_{0}\right)-I_{\text {path }}(z)-I_{\text {sky }}^{(k)}(z)\right\} /\left\{F_{0} \mu_{0} e^{-\frac{\tau_{0}}{\mu_{0}}} e^{-\frac{\tau_{0}-\tau(z)}{\left|\mu_{r}\right|}}\right\}
$$

The iterative procedure of BRDF retrieval may be summarized as follows:

1. On the first iteration $k=1$ initialize: $u^{(\mathrm{k}-1)}=1 \mathrm{~ms}^{-1}, R_{\mathrm{W}}{ }^{(\mathrm{k}-1)}=A_{\mathrm{W}}(\mathrm{k}-1)=0, R$ $=R_{\mathrm{CM}}{ }^{(\mathrm{k}-1)}$.

2. Compute $I_{\text {sky }}{ }^{(k)}(z ; R)$.

3. Compute the full BRDF for all view angles of the CAR using:

$$
R^{(k+1)}=\left\{I_{C A R}-I_{\text {path }}(z)-I_{\text {sky }}^{(k)}(z)\right\} /\left\{F_{0} \mu_{0} e^{\left.-\frac{\tau_{0}}{\mu_{0}} e^{-\frac{\tau_{0}-\tau(z)}{\left|\mu_{r}\right|}}\right\}}\right.
$$

4. In the glint region, defined as $R^{(\mathrm{k}+1)}\left(\mu_{0}, \mu_{\mathrm{r}}, \Delta \phi\right)>\max \left(R_{\mathrm{W}}{ }^{(\mathrm{k})}, 0.02\right)$, find the best-fit wind speed $u^{(\mathrm{k}+1)}$ for the difference $R^{(\mathrm{k}+1)}-R_{\mathrm{W}}{ }^{(\mathrm{k})}$, and update $R_{\mathrm{CM}}{ }^{(\mathrm{k}+1)}$.

5. Update $R_{\mathrm{W}}$ and average water-leaving albedo over the dark ocean.

For angles $\left(\theta_{\mathrm{r}}^{\mathrm{j}}, \phi_{\mathrm{r}}^{\mathrm{j}}\right)$ where $R_{\mathrm{CM}}{ }^{(\mathrm{k}+1)}<0.001$, compute $R_{\mathrm{W}^{(\mathrm{k}+1)}=R^{(\mathrm{k}+1)}-}$ $R_{\mathrm{CM}}{ }^{(\mathrm{k}+1)}$. Next, find the average water-leaving albedo $A_{\mathrm{W}}{ }^{(\mathrm{k}+1)}=N^{-1} \sum_{\mathrm{j}} R_{\mathrm{W}, \mathrm{j}}{ }^{(\mathrm{k}+1)}$, which substitutes $R_{\mathrm{W}}$ for the glint region in the direct reflected radiance, and is used to find the diffuse reflected radiance. In this step, we eliminated high zenith angles $\left(\theta_{\mathrm{r}}>60^{\circ}\right)$, where the retrieved BRDF exhibits strongly nonLambertian behavior and becomes more sensitive to the uncertainties in the atmospheric properties (aerosol, water vapor, and atmospheric inhomogeneity).

6. Repeat iteration from step 2 until the wind speed and the water-leaving albedo stabilize.

This procedure is repeated twice. The first stage serves to retrieve a best estimate of the wind speed. The processing is performed independently for different spectral bands, so the magnitude of the dispersion between independent re- 
trievals serves as an additional quality indicator. After this iteration, the average wind speed is fixed and used in all spectral bands to retrieve the water-leaving BRDF and albedo.

Figure 3 illustrates this iterative procedure for performing atmospheric correction and deriving surface wind speed from multispectral CAR measurements. While processing experimental data we found that in the blue band the convergence strongly depended on an initial guess of $R_{W}(\mathrm{k}=0)$. Convergence can be weak with the solution fluctuating around the true value. To remedy this situation, we used the relaxation technique based on the value from the previous iteration:

$$
A_{W}^{(k+1)}=A_{W}^{k}+\alpha\left\{\frac{1}{N} \sum_{j=1, N} R_{W, j}^{(k+1)}-A_{W}^{k}\right\}
$$

where, $\alpha$ is a relaxation parameter. We found that using $\alpha=0.7$ ensures stable convergence in 2-4 iterations for all of the processed cases both in clear and hazy conditions.

When calculating $R_{\mathrm{W}}(\mathrm{k})$, we eliminated the high zenith angles $\left(\theta>60^{\circ}\right)$, because the retrieved BRDF becomes very sensitive to uncertainties in the atmospheric properties (in situ aerosol, water vapor, and atmospheric homogeneity).

Although the CAR channels were carefully selected in the atmospheric windows, there is still an appreciable amount of absorption by water vapor and atmospheric oxygen. We calculated the line-by-line gaseous absorption based on the latest HITRAN-2000 spectroscopic database (Rothman et al. 2001, 2002) for the US-76 standard atmospheric profile using the Voigt line shape. A step of 0.01 $\mathrm{cm}^{-1}$ in the shortwave region of interest guarantees resolution of lines of major atmospheric gases whose half-width typically exceeds $0.04-0.05 \mathrm{~cm}^{-1}$. As an ex- 
ample, Fig. 4 shows the calculated vertical atmospheric transmission of water vapor at $\lambda=1.219 \mu \mathrm{m}$ averaged over $1 \mathrm{~cm}^{-1}$ for total column water vapor $q=3.15$ $\mathrm{g} \mathrm{cm}^{-2}\left(2.16 \mathrm{~g} \mathrm{~cm}^{-2}\right.$ above the aircraft) on 10 July 2001.

Since gaseous absorption decreases the magnitude of the glint reflectance and slightly decreases the width of the distribution, it affects the wind speed retrievals in our algorithm. The difference in gaseous absorption among CAR channels leads to an additional dispersion in the retrieved velocities of the wind. After explicitly accounting for gaseous absorption, we found that the dispersion of the retrieved wind speed among different CAR channels decreased by about $0.5 \mathrm{~ms}^{-1}$.

\section{b. Auxiliary data for atmospheric correction}

The aerosol and water vapor distribution for each of the two layers of the atmosphere (with interfaces at $H=0.0, \sim 0.2$, and $100.0 \mathrm{~km}$ ) were determined from the 14-channel Ames Airborne Tracking Sun-photometer (AATS-14; Redemann et al. 2004). AATS-14 obtained measurements of aerosol optical depth and water vapor at 14 discrete channels in the UV, visible and near-infrared regions of the electromagnetic spectrum at the same locations and time as the CAR BRDF measurements, thereby characterizing the atmosphere above the airplane. In order to estimate the total aerosol optical thickness and water vapor, we used the AATS measurements at the lowest flight altitude $(\sim 50 \mathrm{~m})$ closest in time to the BRDF observations. The concurrent sun-photometer measurements of the Aerosol Robotic Network (AERONET) at the Chesapeake Lighthouse were used to constrain and adjust our estimates of the total column aerosol optical thickness and water vapor content. To model aerosol optical properties, we used the AERONET size distribution and index of refraction (Dubovik et al. 2002). Fur- 
ther, we assumed that the aerosol phase function and single scattering albedo were the same above and below the airplane.

Thus, we established a procedure for processing CAR data involving monochromatic radiative transfer with the Cox-Munk surface reflectance model and accounting for gaseous absorption and the water-leaving radiance in the CAR channels.

\section{c. Illustration of atmospheric correction}

In this section we apply the algorithm on measurements taken on 17 July near Chesapeake Light as a way to illustrate its performance. On this day the AATS aerosol optical depth is much higher than on any other day during the field experiment (see Fig. 5). For example, $\tau_{\mathrm{a}}(0.472 \mu \mathrm{m})=0.423$ on $17 \mathrm{July}$, and was less than 0.2 on all the other flight days. Other ancillary information like the water vapor column needed for atmospheric correction is also available. This makes it a good case to test the robustness of this atmospheric correction algorithm.

Figure 6a shows a transect of reflectance through the principal plane (the vertical plane containing the Sun) for five discrete wavelengths between 0.472 and $1.219 \mu \mathrm{m}$ as seen from the Convair CV-580 aircraft. The reflectance curves are given as a function of the angle of observation $-80^{\circ} \leq \theta \leq 80^{\circ}$. With this notation, the negative angles represent backscattering directions and the positive angles forward scattering directions. The surface wind was $6.14 \mathrm{~ms}^{-1}$ (measured at $43.3 \mathrm{~m}$ ), and the average solar zenith angle $\theta_{0}=16.23^{\circ}$. As expected, the maximum reflectance values at these solar wavelengths are near the angle for specular reflection from the ocean spread into a range of observation angles. As we move away from this broad solar image peak, the reflected radiance starts to fall 
off rapidly before starting to increase more rapidly, especially in the forward direction, due to multiple scattering effects of the atmosphere. Since Rayleigh scattering decreases with $\lambda$, we see relatively more scattering in the blue $(\lambda=$ $0.472 \mu \mathrm{m})$ as we move towards the horizon. Using the new algorithm, we removed the effects of Rayleigh scattering, aerosol attenuation, and ozone and water vapor absorption. Figure $6 \mathrm{~b}$ shows the resulting curves for reflected radiance just above the ocean. To obtain these results we specified the aerosol optical depth above the airplane (details of aerosol measurements during CLAMS are found in a paper by Redemann et al., this issue). As explained in section $3 b$, the total aerosol optical thickness and water vapor were estimated from the AATS measurements at the lowest flight altitude $(\sim 50 \mathrm{~m})$ closest in time to the BRDF measurements. The aerosol-scattering function and single scattering albedo, $\omega_{\lambda}$, are determined by Mie theory for a lognormal size distribution of aerosol derived from AERONET measurements at Chesapeake Lighthouse on 17 July.

Thus, using the new algorithm, we retrieved atmospherically corrected $\mathrm{BRDF}, R_{\lambda}$ just above the ocean surface that retains specific features of the measured reflectance in the direction of the measurements. We now discuss results of all the cloud-free BRDF measurements acquired during CLAMS.

\section{Results and discussions}

Table 3 shows information on location, date, time, and general conditions of our measurements for seven cloud-free BRDF experiments. The average wind speeds range from 1-11 $\mathrm{ms}^{-1}$. The Sun was generally high, and the range of solar zenith angles was relatively narrow $\left(15-33^{\circ}\right)$. One exception is the case of 2 August, when solar zenith angle was on average $44^{\circ}$. The measurements (10 July, 17 July, 30 July and 2 August) were obtained in the vicinity of the NOAA 
Station CHLV2 (Chesapeake Light; $36.91^{\circ} \mathrm{N}, 75.71^{\circ} \mathrm{W}$ ) where ocean water depth is $11 \mathrm{~m}$. The station is located $\sim 20 \mathrm{~km}$ off Virginia Beach on the eastern coast of the U.S. The other experiments were conducted around three different NOAA Buoy Stations: $44009\left(38.46^{\circ} \mathrm{N}, 74.70^{\circ} \mathrm{W}\right.$; water depth $\left.28 \mathrm{~m}\right)$ on $23 \mathrm{July}, 44014$ $\left(36.58^{\circ} \mathrm{N}, 74.84^{\circ} \mathrm{W}\right.$; water depth $\left.47 \mathrm{~m}\right)$ on $26 \mathrm{July}$, and $44004\left(38.50^{\circ} \mathrm{N}, 70.47^{\circ} \mathrm{W}\right.$; water depth $3160 \mathrm{~m}$ ) on 31 July. The actual locations of BRDF measurements relative to the Buoy stations are shown in Fig. 1. The background image in this figure is the MODIS true color image from EOS Terra acquired on 13 April 2003. A suitable image free from clouds and/or sunglint for the period of measurements was not available.

Since the CAR BRDF measurements were obtained at an altitude of $\sim 200 \mathrm{~m}$ above sea level with the instrument in the nose cone of University of Washington Convair CV-580 (dimensions: length $=25.0 \mathrm{~m}$, height $=9.0 \mathrm{~m}$, wing span $=32.2$ $\mathrm{m})$, the aircraft shadow was observed to contaminate the data. The shadow appears in the data as an anomalously dark zone in the anti-solar plane $\left(\phi=180^{\circ}\right)$ and in directions corresponding to $\theta=\theta_{0}$. The shadow is observed in all bands, but is most distinct at $0.472 \mu \mathrm{m}$. We have compared pixel level data in the shadow and outside the shadow. The maximum reflectance differences range from 0.004 to 0.009 at $0.472 \mu \mathrm{m}$. The differences are less than 0.004 at $0.682 \mu \mathrm{m}$ and $0.870 \mu \mathrm{m}$. We could have minimized the shadowing effect had the measurements been obtained from a much higher altitude, say $H>600 \mathrm{~m}$. This would, on the other hand, have meant decreasing the spatial resolution of our measurements and increasing the uncertainty of atmospheric correction that we wanted to minimize. A similar effect of self-shadowing is reported by Morel et al. (1995) for measurements made aboard a ship with a submersible camera system (Voss 1989). 
Because of the high resolution of our measurements both angular $\left(1^{\circ}\right)$ and spatial (better than $4 \mathrm{~m}$ at nadir) coupled with high SNR (cf. Table 2) and small quantization interval ( 16 bits), we are able to see the radiance field above the ocean in unprecedented detail. In the following subsections we show the full BRDF with several patterns of sunglint and with notable anisotropy of the waterleaving radiance corresponding to various illumination and environmental conditions of our measurements. While discussing water-leaving BRDF, we will focus on three spectral channels $(\lambda=0.472,0.682$ and $0.870 \mu \mathrm{m})$ that are used widely in remote sensing of ocean color and aerosol over the ocean. These wavelengths allow us to examine ocean optical properties for spectral regions with high transmission in the ocean (e.g., $\lambda=0.472 \mu \mathrm{m}$ ) and greater absorption of light in the ocean (e.g., $\lambda=0.870 \mu \mathrm{m})$.

\section{a. Full ocean BRDF}

Figure 7 shows BRDFs, $R_{0.472}(\theta, \phi)$, just above the ocean surface for $0^{\circ} \leq \theta \leq$ $80^{\circ}$ and $0^{\circ} \leq \phi \leq 360^{\circ}$; where $\phi$ represents the azimuth difference between CAR viewing azimuth and the sun azimuth $\left(\phi=\phi_{C A R}-\phi_{0}\right)$ for the seven cloud free cases. Figures $7 \mathrm{~h}$ and $7 \mathrm{i}$ show transects of reflectance through the principal and perpendicular planes for the seven cases shown in the polar plots. Each case represents a different combination of solar zenith angle and wind condition as shown in Fig. 7h. It is interesting to note that for all cases except for Fig. 7f, which represents the BRDF of deep ocean belonging to oceanic case I waters (open waters), the rest of these observations were obtained close to the coastline that appear to be case II waters. According to Morel (1988), the optical properties of case I waters are mainly influenced by the concentration of phytoplankton and their derivative products, whereas the properties of case II waters are influenced 
by suspended sediments or dissolved yellow substance. Morel further observes that: "in absence of terrigenous influx (along arid coasts) and of re-suspended sediment from the shelf, coastal waters can also, and often do, belong to case I". Although it is feasible that the waters we obtained BRDF measurements over may have been under the influence of deep ocean waters, we see a marked contrast in BRDF pattern from the locations close to the coastline and open ocean.

We chose to separate our discussion of the sunglint pattern from the waterleaving radiance because of the large difference in magnitude of the signals from the sunglint and water-leaving radiance that makes it hard to compare them on the same linear scale. Furthermore, the two have different histories; the sunglint seems to be well studied, whereas the water-leaving radiance is much less studied, and for a long time was regarded as dark ocean.

\section{b. Sunglint BRDF}

In each case we studied, we observed a pronounced sun glitter pattern. The glitter pattern consists of numerous instantaneous sunglints produced by direct reflection of the Sun into the directions near the angle of specular reflection from the ocean. The glitter patterns have a shape that is either elliptical (Fig. 7a) or roughly circular (Fig. 7b) with a glint peak ranging from 0.147 (26 July) to 0.631 (10 July), excluding the two cases (23 July and 2 August) when the detector saturated. The peak reflectance does not seem to occur always in the principal plane. For example, on 10 July the peak reflectance in the principal plane $\left(\phi=0^{\circ}\right)$ is 0.572 at $\theta=22^{\circ}$, whereas the actual peak $(0.631)$ occurs at $\theta=22^{\circ}$ and $\phi=353^{\circ}$. Table 4 shows the peak reflectance and its geometrical location, not only at $\lambda=$ $0.472 \mu \mathrm{m}$, but also at other CAR spectral channels considered in this study $(0.682$, $0.870,1.036$, and $1.219 \mu \mathrm{m})$. We note that maximum reflectance is not always in 
the principal plane and that the angle of specular reflection is not always coincident in all channels even though the observations were obtained simultaneously with the same system as described in section 2a. We hypothesize that the differences across channels could be caused by differential spectral responses to ocean inherent optical properties.

It is apparent from Fig. 7 that the location and size of the glitter patterns formed by the Sun depend on the location of the solar zenith angle and the roughness of the water surface. It appears the glitter pattern is much wider on days when the wind is strong and the solar zenith angle is relatively large (e.g., 26 July, 30 July, and 31 July). The peak reflectance as seen in Fig. 7 h is dependent upon wind speed and solar zenith angle. High sun angle seems to favor a circular glitter pattern and relatively smaller peak, while a low sun angle favors an elliptical shape elongated towards the horizon and relatively broader peak. The wind direction clearly influences the orientation of the glitter pattern.

Lets now turn to the diffuse radiative regime just above the water surface and outside the glitter pattern.

\section{c. Water-leaving BRDF}

At present, most of our knowledge of the angular distribution of the water leaving radiance comes from theoretical simulations (e.g., Morel et al. 2002, Loisel and Morel 2001; Yan et al. 2002). These studies predict that under all conditions, water-leaving BRDF depends on $\theta_{0}$. It decreases with increasing $\theta_{0}$ because less light penetrates through the air-water surface into the bulk of the water. Furthermore, the studies report that water-leaving BRDF is controlled by single scattering when there is an abundance of absorbing yellow substances and anisotropy is maximal. The anisotropy in case II waters decreases when domi- 
nated by sediment, where multiple scattering prevails.

There are also some measurements of the water-leaving radiance from ships and automatic platforms as part of validation programs of ocean color algorithms (e.g., Hooker and McClain 2000; Zibordi et al. 2002). The standard measurements are only conducted for several angles $\left(\phi-\phi_{0}=90^{\circ}, \theta=30,40,45^{\circ}\right)$ and fixed heights/depths as prescribed by the SeaWiFS Ocean Optics Protocol (Mueller and Austin 1995), and do not represent the full angular distribution. The known problems of underwater measurements are self-shading, and high absorption, especially in the red spectrum, that make extrapolation difficult (Hooker et al. 2002). The above-water measurements need to eliminate the reflected sky-radiance that may be much larger than the water leaving radiance. Fougnie et al. (1999) resolved the problem by making above-water polarimetric measurements at the Brewster angle and a relative azimuth angle of $135^{\circ}$. This geometry allowed them to cut-off the "noise" reflectance from the ocean surface down to about $10^{-4}$ reflectance units, $2-10 \%$ of the signal of interest.

Because the magnitude of the water-leaving reflectance is at least an order of magnitude lower than in the glitter pattern (see also a transect through a plane perpendicular to the principal plane, Fig. 7i), we have eliminated the glint pattern using a threshold defined by $R_{\mathrm{CM}}<0.001$ [see also Eq. (2)]. That is, if computed reflectance for particular measurement geometry is less than 0.001 , then the retrieved BRDF for the corresponding geometry is assumed to be in the diffuse radiative regime. This procedure allows us to eliminate the glint and provides a better view of the small variation in the water-leaving reflectance.

Figure 8 shows transects through the principal and perpendicular planes for all seven cases (now without the glitter pattern) for $\lambda=0.472,0.682$, and 0.870 $\mu \mathrm{m}$. The data points (spaced $1^{\circ}$ apart) in the principal plane are plotted as 
"dots", while those in the perpendicular plane are plotted as "triangles" for each channel. The data points are joined with a thin line; continuous for points in the principal plane and dotted for points in the perpendicular plane. This differentiation makes it easy to follow each case separately. Note the range of view angles for 30 July (Fig. 8g) ranges from $-80^{\circ}$ to $-40^{\circ}$. The reflectance scale is different for each case. Note also the appearance of shadow contamination in the principal plane, especially on 10 and 23 July and 2 Aug (Fig. 8a, c, and f). From Fig. 8c it is apparent that the glint threshold didn't work well in the principal plane. This is caused by a weakness in the Cox-Munk model at low wind speeds where it tends to underestimate reflectance as discussed in a later section.

Figure 8 is interesting in several important ways. The BRDF $R_{0.472}(\theta)<0.02$ for all cases except 31 July (Fig. 8e), which belongs to oceanic case I waters. The BRDF $R_{0.870}$ can be represented as $0.001<R_{0.870}<0.005$ for $\theta \leq 70^{\circ}$ regardless of whether it is in the principal or perpendicular plane. It has been customary to assume that $R_{0.870}=0.000$ in order to make an assessment of aerosol contribution over the ocean (e.g., Gordon and Wang 1994; Zhao and Nakajima 1997). The water-leaving reflectance has a typical shape that depicts near constant values at $\theta \leq 40^{\circ}$, a gradual increase for $40<\theta \leq 60^{\circ}$, and then a relatively steep increase at $\theta>60^{\circ}$. This rule does not seem to apply on 30 July where the wind speed is 11 $\mathrm{ms}^{-1}$.

In Fig. 9 we have selected the cases with low wind speeds: 10 July, 23 July, and 2 August for three channels for intercomparison of the full water-leaving BRDFs and of transects through the perpendicular plane. We see a clear anisotropy of the radiance field on all days, especially at $0.472 \mu \mathrm{m}$. The smooth angular variation makes it easy to fit the data with simple analytical functions. At 0.682 and $0.870 \mu \mathrm{m}, R_{\lambda}$ is weakly dependent on the relative azimuth angle $\phi$, and 
therefore the Lambertian approximation to the radiance field would be valid for these low wind speeds.

These results are in excellent overall agreement with measurements of Fougnie et al. (1999), and of theoretical simulations (e.g., Morel et al. 2002; Loisel and Morel 2001; Yan et al. 2002). For the case of 23 July, the BRDF in the blue band decreases at $\theta>60^{\circ}$, and the cause is not clear to us since the aerosol optical thickness was the lowest overall for this day. For view angles less than $60^{\circ}$ the water leaving radiance is practically isotropic at all wavelengths which to some extent justifies the use of the Lambertian assumption in our algorithm, and more broadly, in the SeaWiFS and MODIS ocean color algorithms. The water-leaving reflectance does not show a strong dependence on solar zenith angle as suggested by theoretical simulations (e.g., Morel et al. 2002; Loisel and Morel 2001).

The derived water-leaving reflectance in all bands is very stable and consistently reproduced despite the low water leaving signal, and rather considerable variability of atmospheric conditions. There are a few cases of small negative reflectance in the NIR band. This may be due to experimental errors, failure of the radiative transfer model, uncertainty of aerosol correction, and/or calibration errors.

\section{d. Ocean albedo and average water-leaving radiance}

In this section we discuss the spectral albedo derived from our measurements (Fig. 10). Theoretically, we define albedo as the ratio of upward propagating to downward propagating irradiance just above the water surface. The upward propagating irradiance includes radiance reflected from the surface into all viewing directions and solid angles and the upward irradiance transmitted through the water surface from the ambient light field within the water. The al- 
bedo therefore depends on the optical properties of the ocean surface and the body of water below, as well as the sky lighting conditions. In this study we derive the spectral albedo by integrating the reflection over the solid angle in all directions. On the other hand, the average water-leaving radiance assuming isotropic distribution is derived by integrating the reflection function outside the glitter pattern for all reflectances less than 0.02 .

The solid lines of Fig. 10 show the spectral albedo as a function of time, computed from an integration of the atmospherically corrected BRDFs. The albedo shows a spectral dependence with values in the blue band $(\lambda=0.472 \mu \mathrm{m})$ significantly and consistently higher than values at other wavelengths $(\lambda=0.682$ and $0.870 \mu \mathrm{m})$. Little variation is noted from day to day except for the deep ocean case of 31 July. On this day there is a significant increase of the albedo at 0.470 $\mu \mathrm{m}$ and a decrease at all other bands. Strong wind and low sun angle seem to favor an increased albedo, as was the case on 30 July and 2 August, respectively. The albedos at $0.472 \mu \mathrm{m}$ for two cases (26 July and 2 August) should be higher than indicated because the detector saturated for some sunglint angles. The spectral albedo ranges from 0.0408 to 0.0511 at $\lambda=0.472 \mu \mathrm{m}$ and from 0.0255 to 0.0348 at $\lambda=0.682 \mu \mathrm{m}$. For near-infrared bands $(\lambda \geq 0.870 \mu \mathrm{m})$, the albedo ranges from 0.0226 to 0.0309 .

The albedo results are in general agreement with theoretical results of Monte-Carlo simulations by Preisendorfer and Mobley (1986) where they noted little dependence of albedo on wind speed for $\theta_{0}<60^{\circ}$. For small solar zenith angles the albedo increases slightly as the wind speed increases from zero, whereas for large solar zenith angles, the albedo decreases markedly as the wind speed picks up (Preisendorfer and Mobley 1986).

The equivalent water-leaving albedo values vary spectrally with high values 
noted in the blue band (dotted lines in Fig. 10). The values at $\lambda=0.472 \mu \mathrm{m}$ ranged from 0.0098 to 0.0243 , at $\lambda=0.682 \mu \mathrm{m}$ the values ranged from 0.0036 to 0.0064 , and for $\lambda=0.870 \mu \mathrm{m}$ the values ranged from 0.0013 to 0.0038 . Little variations are noted from day to day except for the deep ocean case on 31 July. On this day there is a marked increase of the equivalent water-leaving albedo at $0.470 \mu \mathrm{m}$ and a slight decrease at all other bands. There seems to be only a small variation with respect to wind and sun angle.

\section{e. Validation of Cox and Munk model}

With the type of measurements discussed in this study, it's important to validate the widely used Cox-Munk model for predicting surface slope statistics as a function of wind speed over the ocean under the conditions we measured. Our approach involves using the Cox-Munk model to retrieve wind speed $u$ at 10 $\mathrm{m}$, separately in each band, and then use the best-fit $u$ to compute surface reflectance that we then compare with our retrieved sunglint BRDFs.

\section{1) WIND SPEED RETRIEVAL}

The results of the wind speed retrievals are given in the last column of Table 3. For each experiment, the lower line shows the full range over all spectral bands of the retrieved wind speed $u\left(\mathrm{~ms}^{-1}\right)$ associated with a height of $10 \mathrm{~m}$ above the sea level, and the upper line shows the in situ buoy wind speed and the measurement height. We did not apply for any surface drag correction, which could change some of our results by as much as $15 \%$ (Stull 1988).

The results show that the Cox-Munk model reproduces well the total reflected energy in the region of bright glint. As a result, the wind speed retrievals with our algorithm are on average unbiased. The wind speed retrievals with the azimuthally-independent and anisotropic Cox-Munk models produce close re- 
sults for most cases. The spectral dispersion of wind speed is proportional to $u$ with a factor of $0.1-0.15$, in agreement with a decrease of reflectance with an increase of wind speed.

The retrieved $u$ values were typically close for groups of wavelengths $(0.472$, $1.036,1.219 \mu \mathrm{m})$, and $(0.682,0.870 \mu \mathrm{m})$. However, the latter pair of wavelengths are systematically higher by $\sim 0.1 \mathrm{~ms}^{-1}$ for $u<4 \mathrm{~ms}^{-1}$, and by about $1-4 \mathrm{~ms}^{-1}$ for $u$ $=8-11 \mathrm{~ms}^{-1}$. It is not clear why we have this systematic discrepancy.

In a recent publication, Ebuchi and Kizu (2002) performed analysis of a large 5 -year statistical sample of the surface slope distributions derived from the geostationary radiometer in the visible wavelengths, in combination with scatterometer fields of wind speed. They found much less anisotropy and a considerably narrower distribution of slopes than those reported by Cox and Munk. The parameterization of Nakajima and Tanaka (1983) used in our study, which is close to the original Cox-Munk slope parameterization except for low $u$ values, allowed us to obtain a close agreement with the buoy-measured wind speeds. The parameterization of Ebuchi and Kizu (2002) provides similar results at large wind speeds, however it performs poorly at low wind speeds.

In another recent study, Su et al. (2003) reported that both the amplitude and width of the Cox-Munk model is less than that observed in measurements. This implies that the Cox-Munk model underestimates the total reflected solar energy in the bright glint region, which is different from our conclusions based on wind speed retrievals. We should mention though that such a comparison might not be relevant because the conditions of our measurements (relatively high sun and a rather narrow range of solar angles) were similar to the geometry of the Cox and Munk observations, whereas Su et al. (2003) conducted measurements at very low Sun elevations when the Cox-Munk model may not be valid. 


\section{2) ANALYSIS OF COX-MUNK MODEL}

We focused separately on the glint regions of high $\left(R_{\mathrm{CM}}>0.02\right)$ and low $\left(0.001<R_{\mathrm{CM}} \leq 0.02\right)$ reflectance. The high glint region, which is avoided in satellite ocean color remote sensing, is useful for determining the surface wind speed, atmospheric water vapor, and, potentially, aerosol single scattering albedo. The low glint region, which may occupy a large range of angles at high wind speeds and low sun, is of great interest to the ocean color community although the useful signal (water-leaving radiance) may be comparable to the ocean surface reflectance. For example, the current SeaWiFS algorithm masks reflectance with $R_{\mathrm{CM}}>0.005$ (Wang and Bailey 2001). A study by these authors based on the azimuthally-independent Cox-Munk model demonstrated that with the glint correction the range of ocean color retrievals can be expanded to $R_{\mathrm{CM}} \leq 0.01$.

In their original papers, Cox and Munk (1954a, b) stated that the sensitivity of measurements was about 1000 to 1 . In addition, contribution of the diffuse skylight was calculated approximately by assuming isotropic incident radiation. Given that the images were not saturated, we can assume that the range of surface reflectance that had high enough SNR, from which the slope distribution was derived, was limited to a few tenths of a percent. Thus, the lower glint region poses an additional question of accuracy for the Cox-Munk model due to limitations of instrumentation available at the time.

In this study, we separately processed both the isotropic and anisotropic Cox-Munk model with and without the Grams-Charlier expansion. The anisotropic Cox-Munk model is incorporated in the radiative transfer code SHARM only in the direct reflected radiance, while the diffuse radiance is computed with the azimuthally-independent Cox-Munk model. To ensure energy conservation between the direct and diffuse radiation, the upwind $\left(\mathrm{Z}_{\mathrm{x}}{ }^{2}\right)$ and crosswind $\left(\mathrm{Z}_{\mathrm{y}}{ }^{2}\right)$ 
mean slopes were selected to satisfy $\mathrm{Z}_{\mathrm{x}}{ }^{2}+\mathrm{Z}_{\mathrm{y}}{ }^{2}=\sigma^{2}=0.00534 u$. Cox and Munk reported that they observed the range of slope distribution anisotropy $Z_{x}{ }^{2} / Z_{y}{ }^{2}=$ $1-1.8$ with a mean value of 1.34 . In this study, we varied the value of the ratio in the range 1.34-1.50, which only insignificantly affected the wind speed retrievals and had a negligible effect on the diffuse water-leaving reflectance. Below, we present results for $\mathrm{Z}_{\mathrm{x}}{ }^{2} / \mathrm{Z}_{\mathrm{y}}{ }^{2}=1.5$ with zero offset for both upwind and crosswind components.

The results of our approximation of the high glint region by the isotropic and anisotropic (without and with Gram Charlier expansion) Cox-Munk model are shown in Fig. 11. They are given in terms of the difference between retrieved BRDF and computed reflectance (using Cox-Munk model), normalized to the maximum retrieved spectral BRDF, to uniformly represent conditions that are different in the wind speed and solar elevation. Note that the water-leaving component is added to the computed BRDF before calculating the difference. Since the results are similar in all spectral bands and the VIS-NIR bands were saturated at low wind speeds on 23 July and 2 August, we only show the polar plots for $1.036 \mu \mathrm{m}$. In general, the relative accuracy of the Cox-Munk model is better than about $\pm 30 \%$ at the CAR spatial resolution. At small wind speed $(<3$ $\mathrm{ms}^{-1}$ ), the Cox-Munk model underestimates the observed reflectance in the immediate vicinity of the center of the sunglint by $3-20 \%$.

For low glint regions we selected three cases $(26,30$, and 31 July) to show the performance of the model for both isotropic and anisotropic-without and with Gram-Charlier expansion (cf. Fig. 12). The Cox-Munk model performs reasonably well for the cases with medium to high wind speed $(17,26,30$, and 31 July) and poorly for the low wind speed cases ( 10 and 23 July and 2 August). The differences between measurements and Cox-Munk computations in this region of 
low reflectance range between -0.009 and 0.009 . The anisotropic model shows smaller differences in all cases. It is not possible to give further analysis of the low glint region for the ocean color studies because the observation point of the radiometer varied with scan angle, and the variability we observe can be attributed to the horizontal inhomogeneity of the coastal waters. On the other hand, however, our measurements clearly show that low glint regions may pose some problems at low wind speeds.

In cases of medium and high wind speed, the Cox-Munk model with GramCharlier expansion provided the better fit to the measured glint pattern than the isotropic Cox-Munk model, although the improvement was not dramatic (cf. Fig. 13). We certainly need larger statistics to generalize our conclusions further.

\section{Summary and Conclusions}

The Cloud Absorption Radiometer (CAR) was flown aboard the University of Washington Convair CV-580 research aircraft during the CLAMS field experiment where it obtained measurements of bidirectional reflectance distribution function (BRDF) of the ocean during July and August 2001 in conditions of high to medium Sun $\left(15^{\circ}<\theta_{0}<46^{\circ}\right)$. The measurements were accompanied by AATS-14 measurements of atmospheric aerosol and water vapor above the airplane. The properties of the total atmospheric column were evaluated from AATS-14 measurements at the lowest flight altitude $(\sim 50 \mathrm{~m})$. The aerosol size distribution and refractive index were provided by analysis of nearby AERONET sunphotometer measurements at Chesapeake Light. With this ancillary information, we developed a rigorous iterative atmospheric correction algorithm that retrieves simultaneously the wind speed and full ocean BRDF (sunglint and water-leaving reflectance) from CAR measurements. The algorithm was applied to 
seven cloud-free days of measurements conducted over the Atlantic Ocean at COVE, an EOS validation site $\left(35.00^{\circ} \mathrm{N}, 75.68^{\circ} \mathrm{W}\right)$, and at nearby NOAA Buoy stations.

The BRDF from our measurements shows the characteristic anisotropy of the water-leaving radiance, with increases at high view zenith angles $\left(\theta>60^{\circ}\right)$, that is found in simulations. This paper gives examples of the diffuse water-leaving BRDF at wavelengths of $0.472,0.682$, and $0.870 \mu \mathrm{m}$ for different cases. This unique information is important for parameterization of ocean color algorithms for Case II waters and validation analysis. We also present the water-leaving albedo and total spectral albedo of the ocean.

Results of validation of the Cox-Munk model of ocean surface reflectance show that on average the model describes well the glint pattern. As a result, the wind speed retrieved from the bright glint region with reflectance greater than 0.02 on five different cases was within $\pm 0.5 \mathrm{~ms}^{-1}$ of the in situ measurements for the range $1<u<11 \mathrm{~ms}^{-1}$. In the other two cases of medium wind speed $(u=6-8$ $\left.\mathrm{ms}^{-1}\right)$, the difference was larger $\left( \pm 4 \mathrm{~ms}^{-1}\right)$. The retrievals of wind speed with the azimuthally independent Cox-Munk model and the full Cox-Munk model with Gram-Charlier expansion produced very similar results in most cases. The shape of the sunglint was reproduced on average with an accuracy of better than $30 \%$. At low wind speeds $\left(<2-3 \mathrm{~ms}^{-1}\right)$, the Cox-Munk model underestimates the center of the glint reflectance by about $30 \%$. For the dark glint region with reflectance from 0.001 to 0.02 , the standard deviation was on average 0.005 . In cases of high wind speed, the Cox-Munk model with Gram-Charlier expansion provided the best fit.

The results of this study are an important bench mark for further work that would involve extending the observed quantitative behavior to other conditions 
using other analytical models and radiative transfer (RT) simulations of an ocean-atmosphere system. It is also possible to combine our measured albedo and solutions of irradiance models of RT with climatological values of wind speed and water type to generate a detailed atlas of the albedos over the oceans. The recent availability of comprehensive ocean-atmosphere datasets makes such calculations feasible. However, such a project, worthwhile as it is, is beyond the scope of the present paper.

Acknowledgments. The authors are especially grateful to P. V. Hobbs and the University of Washington CV 580 staff members for great assistance in data collection. Thanks also to P. K. Shu, H. H. Jones, and team for engineering support. We express our appreciation for graphics support to: R. B. Simmon and J. E. Schmaltz (Fig. 1); B. Napper, J. A. O'Leary, K. A. Gammage and C. L. Ladd (Fig. 2); and J. Riédi for his support of Mgraph software. We also acknowledge size distribution data derived from AERONET sunphotometer measurements at Chesapeake Light Tower and wind information from NOAA buoy stations. This research was supported by funding provided by NASA's Radiation Science Program, the MODIS Science Team, and the EOS Project Science Office. The study was conducted as part of Chesapeake Lighthouse and Aircraft Measurements for Satellites (CLAMS) experiment. We are grateful to the CLAMS science team, especially W. L. Smith and T. P. Charlock, for their support in coordination and planning of the field campaign. 


\section{References}

Cox, C., and W. Munk, 1954a: The measurements of the roughness of the sea surface from photographs of the sun's glitter. J. Opt. Soc. Am., 44, 838-850. and 1954b: Statistics of the sea surface derived from sun glitter. $J$. Mar. Res., 13, 198-227.

Duntley, S. Q., 1954: Measurements of the distribution of water wave slopes. $J$. Opt. Soc. Am., 44, 574-575.

Dubovik, O., B. N. Holben, T. F. Eck, A. Smirnov, Y. J. Kaufman, M. D. King, D. Tanré, and I. Slutsker, 2002: Variability of absorption and optical properties of key aerosol types observed in worldwide locations. J. Atmos. Sci., 59, 590-608.

Ebuchi, N, and S. Kizu, 2002: Probability distribution of surface wave slope derived using sun glitter images from Geostationary Meteorological Satellite and surface vector winds from scatterometers. J. Oceanogr., 58, 477-486.

Gatebe, C. K., M. D. King, S. Platnick, G. T. Arnold, E. F. Vermote and B. Schmid, 2003: Airborne spectral measurements of surface-atmosphere anisotropy for several surfaces and ecosystems over southern Africa. J. Geophys. Res., 108, doi:10.1029/2002JD002397.

Gordon, H. R., 1997: Atmospheric correction of ocean color imagery in the Earth observing system era. J. Geophys. Res., 102, 17081-17106.

Guinn, Jr. A. J., G. N. Plass, and W. Kattawar, 1979: Sunlight glitter on a windruffled sea: further studies. Appl. Opt., 18, 842-849.

Hooker, S. B., and C. R. McClain, 2000: The calibration and validation of SeaWiFS data. Prog. Oceanogr., 45, 427-465.

G. Lazin, G. Zibordi, G. Zibordi, and S. McLean, 2002: An evaluation of above- and in-water methods for determining water-leaving radiances. $J$. 
Atmos. Oceanic Technol., 19, 486-515.

Hulburt, E. O., 1934: The polarization of light at sea. J. Opt. Soc. Amer., 24, 35-42.

Kaufman, Y. J., J. V. Martins, L. A. Remer, M. R. Schoeberl, and M. A. Yamasoe, 2002: Retrieval of black carbon absorption from proposed satellite measurements over the ocean glint. Geophys. Res. Lett., 29, doi:10.1029/2002GL015403.

Kleidman, R. G., Y. J. Kaufman, B. C. Gao, L. A. Remer, V. G. Brackett, R. A. Ferrare, E. V. Browell, and S. Ismail, 2000: Remote sensing of total precipitable water vapor in the near-IR over ocean glint. Geophys. Res. Lett., 27, 2657-2660.

King, M. D., M. G. Strange, P. Leone, and L. R. Blaine, 1986: Multi-wavelength scanning radiometer for airborne measurements of scattered radiation within clouds. J. Atmos. Oceanic Technol., 3, 513-522.

Loisel, H., and A. Morel, 2002: Non-isotropy of the upward radiance field in typical coastal (case II) waters. Int. J. Remote Sens., 22, 275-295.

Lyapustin A., and T. Z. Muldashev, 1999: Method of spherical harmonics in the radiative transfer problem with non-Lambertian surface. J. Quant. Spectrosc. Radiat. Transfer, 61, 545-555. and 2000: Generalization of Marshak boundary condition for nonLambert reflection. J. Quant. Spectrosc. Radiat. Transfer, 67, 457-464.

Morel, A., and B. Gentili, 1993: Diffuse reflectance of oceanic waters. II Bidirectional aspects. Appl. Optics, 32, 6864-6879. and 1996: Diffuse reflectance of oceanic waters. III Implication of bidirectionality for the remote-sensing problem. Appl. Optics, 35, 4850-4862. D. Antoine, and B. Gentili, 2002: Bidirectional reflectance of oceanic waters: accounting for Raman emission and varying particle scattering phase function. Appl. Optics, 41, 6289-6306. 
K. J. Voss, B. Gentili, 1995: Bidirectional reflectance of oceanic waters: A comparison of modeled and measured upward radiance fields. J. Geophys. Res., 100, 13143-13150.

Mueller, J. L., and R. W. Austin, 1995: Ocean optics protocol for SeaWiFS validation, revision 1. NASA Tech. Memo 104566, S. B Hooker, E. R. Firestone, and J. G. Acker, Eds., 25, NASA Goddard Space Flight Center, 66 pp.

Nakajima, T., and M. Tanaka, 1983: Effect of wind-generated waves on the transfer of solar radiation in the atmosphere-ocean system, J. Quant. Spectrosc. Radiat. Transfer, 29, 521-537.

Preisendorfer, R. W. and C. D. Mobley, 1986: Albedos and glitter patterns of a wind-roughened sea surface. J. Phys. Oceanogr., 16, 1293-1316.

Redemann, J., B. Schmid, J. A. Eilers, R. Kahn, R. C. Levy, P. B. Russell, J. M. Livingston, P. V. Hobbs, W. L. Smith Jr., and B. N. Holben, 2004: Suborbital measurements of spectral aerosol optical depth and its variability at subsatellite grid scales in support of CLAMS, 2001. J. Atmos. Sci., this issue.

Rothman L. S., C. P. Rinsland, A. Goldman, S. T. Massie, D. P. Edwards, J. M. Flaud, A. Perrin, C. Camy-Peyret, V. Dana, J. Y. Mandin, J. Schroeder, A. McCann, R. R. Gamache, R. B. Wattson, K. Yoshino, K. V. Chance, K. W. Jucks, L. R. Brown, V. Nemtchinov, and P. Varanasi, 1998: The HITRAN molecular spectroscopic database and HAWKS (HITRAN atmospheric workstation): 1996 edition. J. Quant. Spectrosc. Radiat. Transfer, 60, 665-710.

Soulen, P. F., M. D. King, S. C. Tsay, G. T. Arnold, and J. Y. Li, 2000: Airborne spectral measurements of surface-atmosphere anisotropy during the SCARA, Kuwait oil fire, and TARFOX experiments. J. Geophys. Res., 105, 10203-10218.

Schooley, A. H., 1954: A simple optical method for measuring the statistical dis- 
tribution of water surface slopes. J. Opt. Soc. Amer., 44, 37-40.

Voss, K. J., 1989: Electro-optic camera system for measurement of the underwater radiance distribution. Opt. Eng., 28, 241-247.

Wang, M. H., and Bailey, S. W., 2001: Correction of sun glint contamination on the SeaWiFS ocean and atmosphere products. Appl. Optics, 40, 4790-4798.

Yan B., K. Stamnes, M. Toratani, W. Li, and J. J. Stamnes, 2002: Evaluation of a reflectance model used in the SeaWiFS ocean color algorithm: implications for chlorophyll concentration retrievals. Appl. Optics, 20, 6243-6259.

Yang, H., and H. R. Gordon, 1997: Remote sensing of ocean color: Assessment of water-leaving radiance bidirectional effects on atmospheric diffuse transmittance. Appl. Optics, 36, 7887-7897.

Zhao, F., and T. Nakajima, 1997: Simultaneous determination of water-leaving reflectance and aerosol optical thickness from Coastal Zone Color Scanner measurements. Appl. Optics, 36, 6949-6956.

Zeiss, C. R. , C. P. MacGrath, and K. M. Littfin, 1999: Infrared radiance of the wind-ruffled sea. J. Opt. Soc. Am., 16, 1439-1452.

Zibordi, G., S. B. Hooker, J. F. Berthon, and D. D'Alimonte, 2002: Autonomous above-water radiance measurements from an offshore platform: A field assessment experiment. J. Atmos. Ocean Tech. 19, 808-819. 


\section{TABLE CAPTIONS}

Table 1. Current Cloud Absorption Radiometer specifications.

Table 2. Signal to noise ratio for CAR measurements during CLAMS.

Table 3. CAR BRDF measurements parameters for CLAMS.

Table 4. Peak glint reflectance and peak reflectance in the principal plane. 
TABLE 1. Current Cloud Absorption Radiometer specifications.

\begin{tabular}{ll}
\hline \hline Platform & University of Washington CV-580 aircraft \\
Ground speed & $80 \mathrm{~m} \mathrm{~s}^{-1}$ (nominal) \\
Total field of view & $190^{\circ}$ \\
Instantaneous field of view & 17.5 mrad (1 $\left.{ }^{\circ}\right)$ \\
Imaging modes & 4 (zenith, BRDF, starboard, nadir) \\
Pixels per scan line & 382 \\
Scan rate & 1.67 scan lines per second $(100 \mathrm{rpm})$ \\
Spectral channels $(\mu \mathrm{m} ;$ & $14(8$ continuously sampled and last six in filter \\
bandwidth (FWHM)) & wheel: $0.340(0.009), 0.381(0.006), 0.472(0.021)$, \\
& $0.682(0.022), 0.870(0.022), 1.036(0.022)$, \\
& $1.219(0.022), 1.273(0.023), 1.556(0.032)$, \\
& $1.656(0.045), 1.737(0.040), 2.103(0.044)$, \\
Output channels & $2.205(0.042), 2.302(0.043)$ \\
Data rate & 9 channels at 16 bits \\
Instrument mass & $61.85 \mathrm{MB}$ hr ${ }^{-1}$ \\
Radiometric calibration & 42 kg \\
& Laboratory integrating sphere measurements be- \\
& fore and after research mission \\
\hline
\end{tabular}


TABLE 2. Signal to noise ratio for CAR measurements during CLAMS.

\begin{tabular}{|c|c|c|c|c|c|c|}
\hline \multirow{2}{*}{$\begin{array}{l}\text { Date } \\
(2001)\end{array}$} & \multicolumn{5}{|c|}{ Signal to noise ratio at $\lambda(\mu \mathrm{m})$} & \multirow{2}{*}{$\begin{array}{c}\text { Number of } \\
\text { Points }\end{array}$} \\
\hline & 0.472 & 0.682 & 0.870 & 1.036 & 1.219 & \\
\hline 10 July & 733 & 133 & 86 & 21 & 19 & 1271 \\
\hline 17 July & 992 & 174 & 118 & 28 & 21 & 1806 \\
\hline 23 July & 775 & 45 & 32 & 8 & 7 & 1207 \\
\hline 26 July & 985 & 110 & 122 & 31 & 26 & 552 \\
\hline 30 July & 924 & 146 & 100 & 23 & 22 & 2121 \\
\hline 31 July & 1544 & 96 & 93 & 23 & 24 & 651 \\
\hline 2 August & 596 & 50 & 28 & 7 & 5 & 2511 \\
\hline
\end{tabular}


TABLE 3. CAR BRDF measurements parameters for CLAMS.

\begin{tabular}{ccccc}
\hline $\begin{array}{c}\text { Date } \\
(2001)\end{array}$ & $\begin{array}{c}\text { Time } \\
(\mathrm{UTC})\end{array}$ & Location & $\begin{array}{c}\text { Solar } \\
\left(\theta_{0}, \phi_{0}\right)\left({ }^{\circ}\right)\end{array}$ & $\begin{array}{c}\text { Measured } u\left(\mathrm{~m} \mathrm{~s}^{-1}\right), \text { alt. } \\
\left(\text { retrieved } u^{\mathrm{a}} ; 10 \mathrm{~m}\right)\end{array}$ \\
\hline 10 July & $18: 04-18: 19$ & $36.96^{\circ} \mathrm{N}$, & $19-22$, & $1.58 ; 43.3 \mathrm{~m}$ \\
& & $75.70^{\circ} \mathrm{W}$ & $223-231$ & $(2.1-2.4)$ \\
17 July & $16: 46-17: 05$ & $36.96^{\circ} \mathrm{N}$, & $15-16$, & $6.14 ; 43.4 \mathrm{~m}$ \\
& & $75.72^{\circ} \mathrm{W}$ & $160-177$ & $(4.1-4.6)$ \\
23 July & $15: 01-15: 18$ & $37.82^{\circ} \mathrm{N}$, & $29-33$, & $1.08 ; 5 \mathrm{~m}$ \\
& & $74.36^{\circ} \mathrm{W}$ & $115-121$ & $(1.1-1.2)$ \\
26 July & $17: 48-18: 06$ & $36.48^{\circ} \mathrm{N}$, & $19-22$, & $9.10 ; 5 \mathrm{~m}$ \\
& & $74.51^{\circ} \mathrm{W}$ & $211-223$ & $(9.6-11.5)$ \\
30 July & \multirow{2}{*}{$19: 05-19: 19$} & $37.09^{\circ} \mathrm{N}$, & $31-35$, & $10.56 ; 43.3 \mathrm{~m}$ \\
& & $75.61^{\circ} \mathrm{W}$ & $241-246$ & $(9.5-13.1)$ \\
31 July & $16: 52-17: 06$ & $38.55^{\circ} \mathrm{N}$, & $20-21$, & $8.41 ; 4 \mathrm{~m}$ \\
& & $70.64^{\circ} \mathrm{W}$ & $182-192$ & $(10.0-11.3)$ \\
2 August & $20: 00-20: 19$ & $37.08^{\circ} \mathrm{N}$, & $42-46$, & $2.88 ; 43.3 \mathrm{~m}$ \\
& & $75.68^{\circ} \mathrm{W}$ & $254-259$ & $(2.6-2.7)$ \\
\hline \hline
\end{tabular}

a - computed using Cox-Munk model as described in section 3a. 
TABLE 4. Peak glint reflectance and peak reflectance in the principal plane.

\begin{tabular}{|c|c|c|c|c|c|c|}
\hline \multirow{2}{*}{$\begin{array}{c}\text { Date } \\
(2001)\end{array}$} & & \multicolumn{5}{|c|}{ Reflectance at $\lambda(\mu \mathrm{m})$} \\
\hline & & 0.472 & 0.682 & 0.870 & 1.036 & 1.219 \\
\hline \multirow[t]{4}{*}{10 July } & Peak $R$ & 0.631 & 0.611 & 0.569 & 0.649 & 0.632 \\
\hline & $(\theta, \phi)$ & $(21,353)$ & $(20,5)$ & $(23,354)$ & $(20,5)$ & $(20,5)$ \\
\hline & Peak $R^{\mathrm{P}}$ & 0.572 & 0.524 & 0.502 & 0.561 & 0.546 \\
\hline & $(\theta, \phi)$ & $(22,0)$ & $(22,0)$ & $(22,0)$ & $(22,0)$ & $(22,0)$ \\
\hline \multirow[t]{4}{*}{17 July } & Peak $R$ & 0.355 & 0.337 & 0.338 & 0.355 & 0.354 \\
\hline & $(\theta, \phi)$ & $(16,354)$ & $(18,3)$ & $(15,355)$ & $(16,354)$ & $(15,355)$ \\
\hline & Peak $R^{\mathrm{P}}$ & 0.305 & 0.284 & 0.285 & 0.300 & 0.297 \\
\hline & $(\theta, \phi)$ & $(15,0)$ & $(15,0)$ & $(15,0)$ & $(15,0)$ & $(17,0)$ \\
\hline \multirow[t]{4}{*}{ *23 July } & Peak $R$ & 0.532 & 1.092 & 0.854 & 1.836 & 1.869 \\
\hline & $(\theta, \phi)$ & $(32,347)$ & $(32,355)$ & $(32,356)$ & $(32,355)$ & $(32,355)$ \\
\hline & Peak $R^{\mathrm{P}}$ & 0.506 & 0.964 & 0.813 & 1.438 & 1.455 \\
\hline & $(\theta, \phi)$ & $(32,0)$ & $(32,0)$ & $(32,0)$ & $(32,0)$ & $(32,0)$ \\
\hline \multirow[t]{4}{*}{26 July } & Peak $R$ & 0.147 & 0.125 & 0.123 & 0.134 & 0.136 \\
\hline & $(\theta, \phi)$ & $(18,8)$ & $(18,8)$ & $(18,8)$ & $(24,351)$ & $(24,351)$ \\
\hline & Peak $R^{P}$ & 0.129 & 0.112 & 0.110 & 0.119 & 0.122 \\
\hline & $(\theta, \phi)$ & $(19,0)$ & $(10,0)$ & $(10,0)$ & $(18,0)$ & $(18,0)$ \\
\hline \multirow[t]{4}{*}{30 July } & Peak $R$ & 0.245 & 0.238 & 0.226 & 0.235 & 0.246 \\
\hline & $(\theta, \phi)$ & $(37,345)$ & $(51,348)$ & $(54,351)$ & $(37,345)$ & $(37,345)$ \\
\hline & Peak $R^{\mathrm{P}}$ & 0.193 & 0.185 & 0.176 & 0.175 & 0.184 \\
\hline & $(\theta, \phi)$ & $(51,0)$ & $(51,0)$ & $(51,0)$ & $(43,0)$ & $(43,0)$ \\
\hline \multirow[t]{4}{*}{31 July } & Peak $R$ & 0.198 & 0.156 & 0.149 & 0.167 & 0.164 \\
\hline & $(\theta, \phi)$ & $(22,9)$ & $(22,9)$ & $(22,8)$ & $(22,8)$ & $(33,2)$ \\
\hline & Peak $R^{\mathrm{P}}$ & 0.173 & 0.139 & 0.135 & 0.148 & 0.148 \\
\hline & $(\theta, \phi)$ & $(20,0)$ & $(20,0)$ & $(20,0)$ & $(20,0)$ & $(20,0)$ \\
\hline \multirow[t]{4}{*}{ *2 August } & Peak $R$ & 0.773 & 1.253 & 1.046 & 1.331 & 1.402 \\
\hline & $(\theta, \phi)$ & $(44,358)$ & $(50,357)$ & $(47,2)$ & $(45,2)$ & $(45,2)$ \\
\hline & Peak $R^{\mathrm{P}}$ & 0.744 & 1.028 & 0.971 & 1.050 & 1.118 \\
\hline & $(\theta, \phi)$ & $(51,0)$ & $(47,0)$ & $(47,0)$ & $(47,0)$ & $(47,0)$ \\
\hline
\end{tabular}

$R^{\mathrm{P}}:$ Reflectance in the principal plane

${ }^{*}: \lambda=0.472,0.682$, and 0.870 saturated 


\section{FIGURE CAPTIONS}

Fig. 1. Locations of airborne measurements of bidirectional reflectance distribution function (BRDF) obtained during the CLAMS field experiment from 10 July - 2 August 2001 using NASA's Cloud Absorption Radiometer (CAR). The background image on which the BRDF locations are mapped is a true color composite of Moderate Imaging Spectroradiometer (MODIS) surface reflectance produced from atmospherically corrected 8-day MODIS reflectance data product.

Fig. 2. Schematic representation of the BRDF measurements with Cloud Absorption Radiometer (CAR), scanning the surface from $200 \mathrm{~m}$ above the ocean surface as the aircraft makes a clockwise circular flight-track. The radiance detected by the CAR may be broken down into four components: path radiance $\left(I_{\text {path }}\right)$, sky radiance $\left(I_{\text {sky }}\right)$, sunglint radiance $\left(I_{\text {sun }}\right)$, and radiance backscattered by the hydrosols to the CAR represented by $I_{\text {water. }}$ The inset (modified after Zeiss et al. 1999) shows the geometry of facet reflection with unit vectors $U_{\mathrm{s}}$ and $U_{\mathrm{r}}$ pointing toward the Sun and the CAR, respectively, from the origin of a right-handed coordinate system located at the reflection point.

Fig. 3. Flow diagram for atmospheric correction of CAR BRDF measurements.

Fig. 4. Calculated vertical atmospheric transmission of water vapor averaged over $1 \mathrm{~cm}^{-1}$ for the CAR band at a wavelength of $1.219 \mu \mathrm{m}$ for total column water vapor $q=3.15 \mathrm{~g} \mathrm{~cm}^{-2}\left(2.16 \mathrm{~g} \mathrm{~cm}^{-2}\right.$ above the aircraft) on 10 July 2001. The spectral response function at the same wavelength is superimposed.

Fig. 5. Variation of $\tau_{\mathrm{a}}$ aircraft $(\lambda)$ as measured by Ames Airborne Tracking Sunphotometer (AATS) during the CLAMS field experiment campaign at 
the time of BRDF measurements.

Fig. 6. Illustration of atmospheric correction. Panels (a) and (b) show the angular distribution of bidirectional reflectance in the principal plane for measurements taken on 17 July 2001 at $\left(36.96^{\circ} \mathrm{N}, 75.72^{\circ} \mathrm{W}\right)$ in the vicinity of Chesapeake Light $\left(36.91^{\circ} \mathrm{N}, 75.71^{\circ} \mathrm{W}\right)$ before and after atmospheric correction. Panels (c) through (g) show the full atmospherically corrected BRDF for five CAR spectral channels in the visible and nearinfrared. The broad reflectance peak represent the sunglint for an average solar zenith angle $\theta_{0}=16.23^{\circ}$.

Fig. 7. Spectral BRDF at $0.472 \mu \mathrm{m}$ for seven cloud-free cases obtained by CAR between 10 July and 2 August 2001 during CLAMS. The transects through and perpendicular to the plane of the Sun are also given. The effect of different illumination and wind conditions on the intensity, size, orientation, and location of sunglint are clearly seen.

Fig. 8 Water-leaving BRDF in the principal and perpendicular plane of the Sun at three CAR channels $(0.472,0.682$, and $0.870 \mu \mathrm{m})$ for seven cloudfree cases with various conditions. On average, even though the illumination conditions are different, water-leaving BRDFs do not seem to vary much from case to case. Note that 31 July measurements were obtained in deep Ocean unlike the other cases where measurements were obtained in the proximity of the coastline. The sunglint has been cutoff so as to be able to amplify the low varying BRDFs.

Fig. 9 Comparison of spectral BRDF for cases with low wind speeds on 10 and 23 July and 2 August at three CAR channels $(0.472,0.682$, and $0.870 \mu \mathrm{m})$ and with the sunglint cutoff to allow us to see more details of the variation of BRF with view zenith angle. 
Fig. 10 Total ocean spectral albedo and average water-leaving (total albedo excluding the sunglint) for seven cloud-free cases of CAR measurements over the Atlantic off the U.S. east coast during the CLAMS field experiment campaign from 10 July - 2 August 2001.

Fig. 11 Normalized differences between measurements and computed reflectance using isotropic Cox-Munk, and anisotropic Cox-Munk without and with Gram Charlier expansion (a to g) for the brightest part of the sunglint where computed reflectance $R>0.02$. (h) shows the differences for the entire high glint region for $31 \mathrm{July}$, to serve as an illustration for the other cases.

Fig. 12. Differences between measurements and computed reflectance using isotropic Cox-Munk, and anisotropic Cox-Munk without and with Gram Charlier expansion in the darkest part of the sunglint reflectance $(0.001<R<0.02)$.

Fig. 13. Comparison of differences between measurements and computed reflectance using anisotropic Cox-Munk with Gram Charlier expansion for both high glint an low glint for the three cases with strongest wind $\left(8-11 \mathrm{~ms}^{-1}\right)$. 


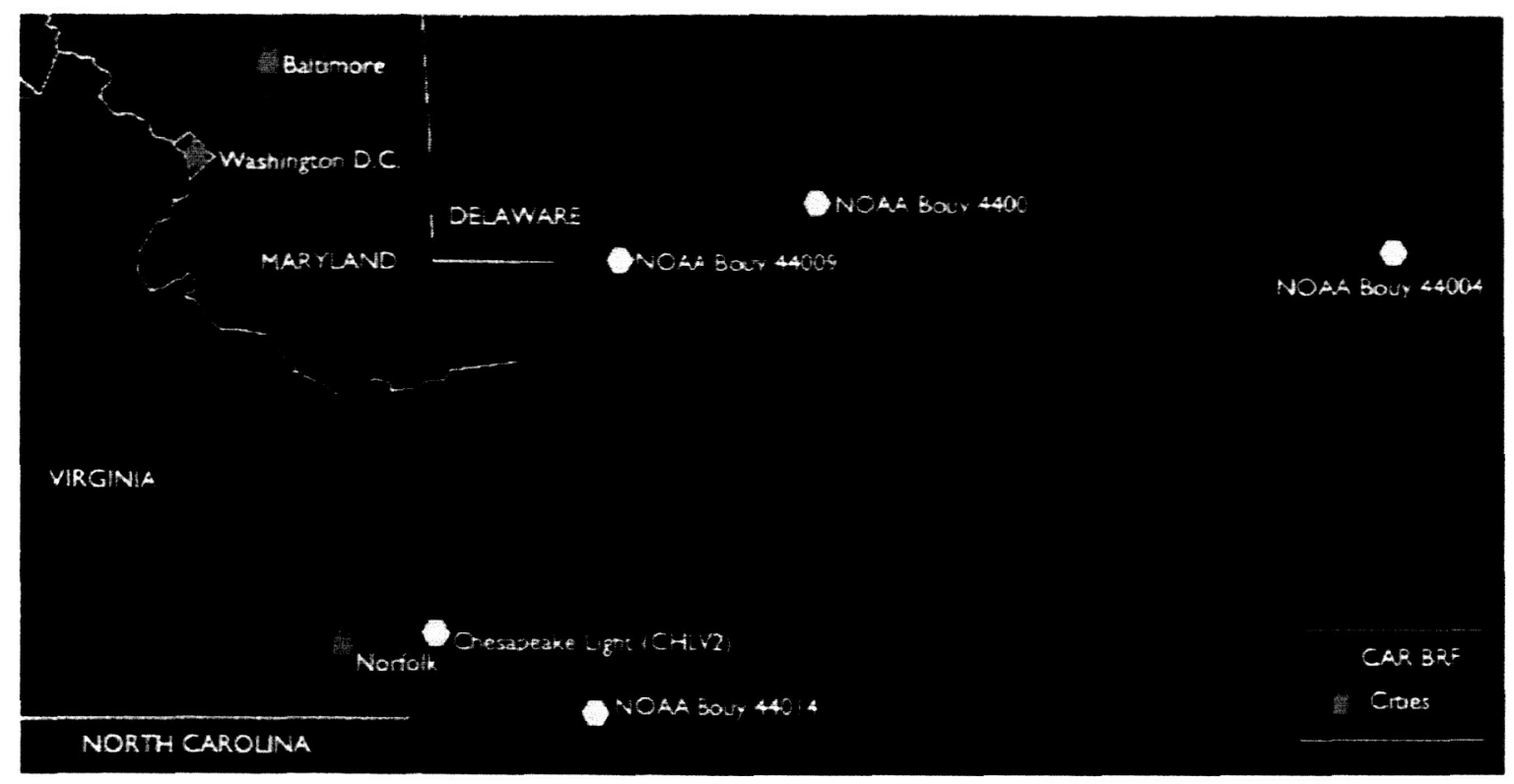

Figure. 1. Locations of airborne measurements of bidirectional reflectance distribution function (BRDF) obtained during the CLAMS field experiment from 10 July- 2 August 2001 using NASA's Cloud Absorption Radiometer (CAR). The background image on which the BRDF locations are mapped is a true color image of Terra Moderate Imaging Spectroradiometer (MODIS) acquired on 13 April of 2003. 


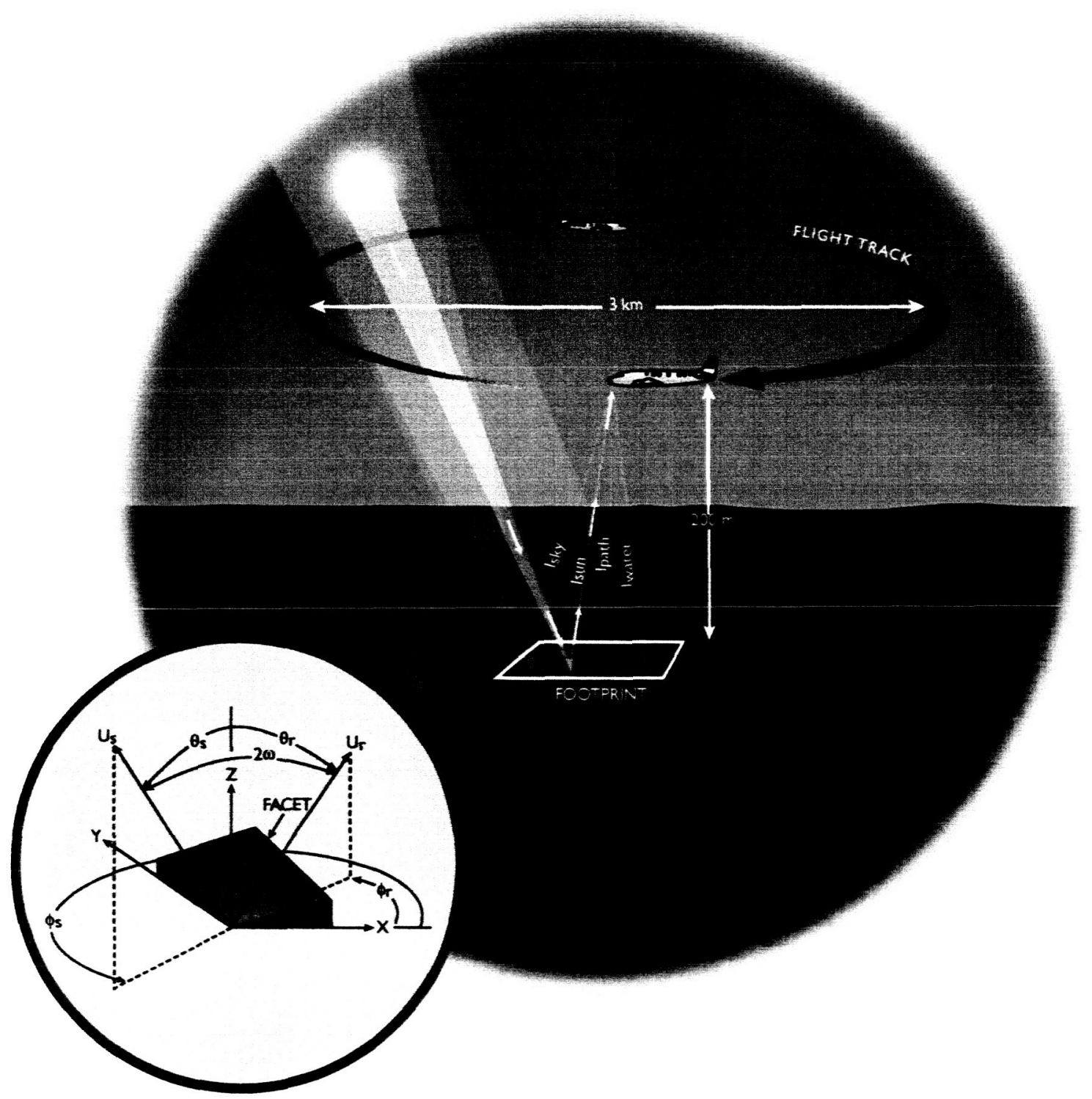

Figure 2. Contributions to instant ocean radiance received by CAR aboard an aircraft scanning the surface from a height $\mathrm{H}$ meters above as the aircraft traces a clockwise circular flight track for measuring surface bidirectional reflectance from nadir to the horizon, as well as much of the transmittance from near zenith to the horizon. The inset (modified after Zeiss et al. 1999) shows the geometry of facet reflection with unit vectors $U_{\mathrm{s}}$ and $U_{\mathrm{r}}$ pointing toward the Sun and the sensor, respectively, from the origin of a right-handed coordinate system located at the reflection point. 


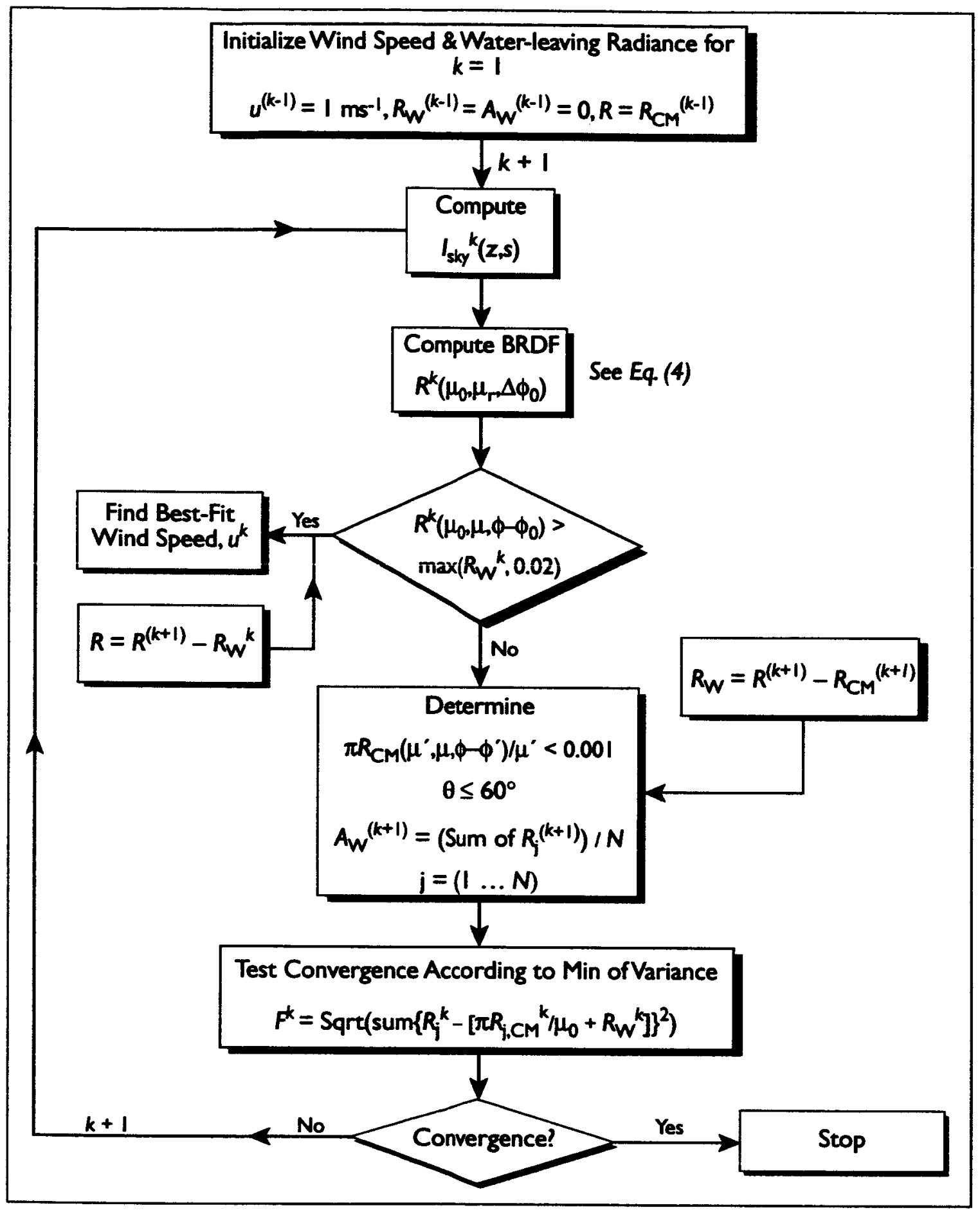

Figure 3. Flow diagram for atmospheric correction of CAR BRDF measurements. 


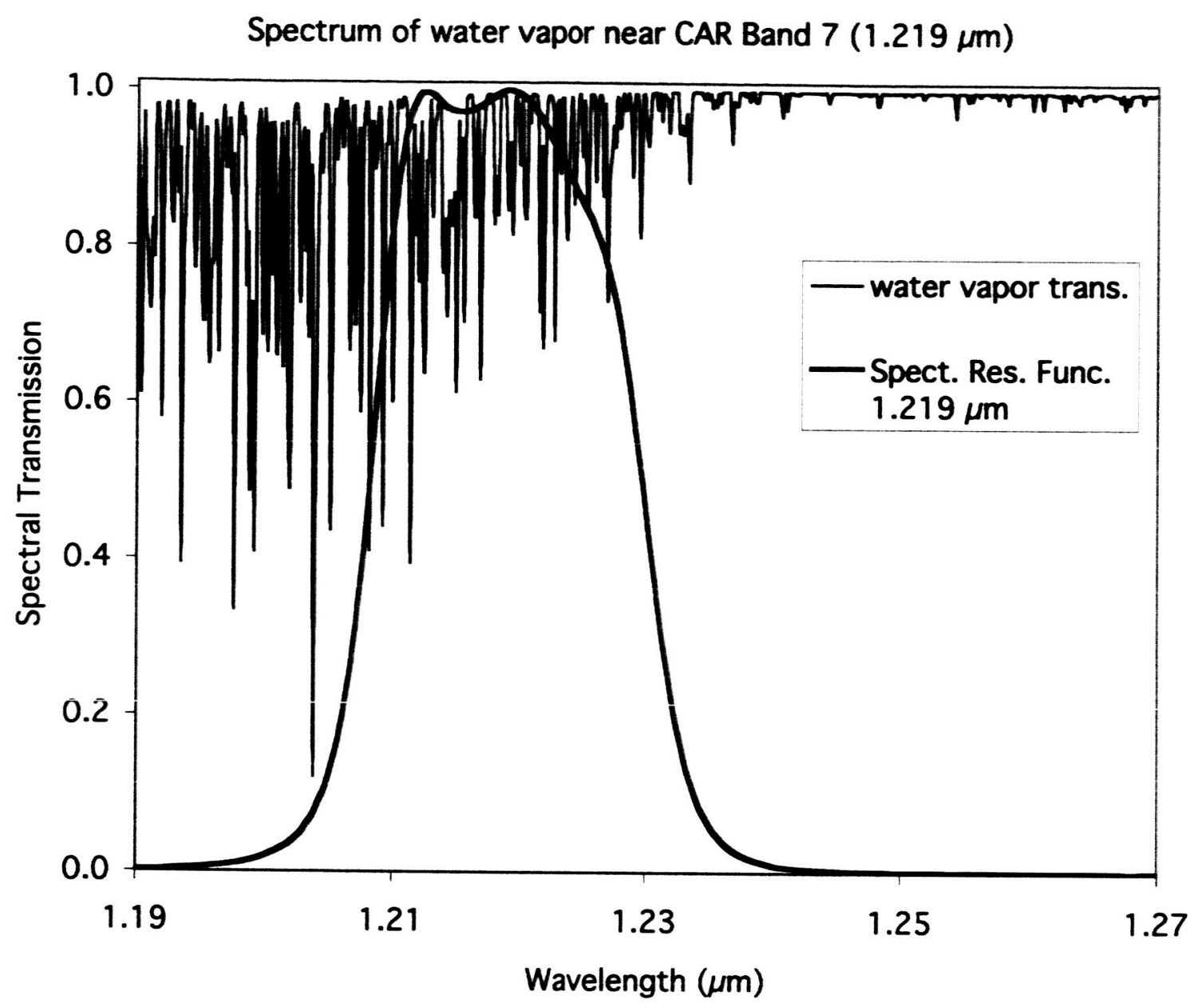

Figure 4. Calculated vertical atmospheric transmission of water vapor averaged over $1 \mathrm{~cm}^{-1}$ for the CAR band at a wavelength of $1.219 \mu \mathrm{m}$ for total column water vapor $q=3.15 \mathrm{~g} \mathrm{~cm}^{-2}\left(2.16 \mathrm{~g} \mathrm{~cm}^{-2}\right.$ above the aircraft) on 10 July 2001. The spectral response function at the same wavelength is superimposed. 


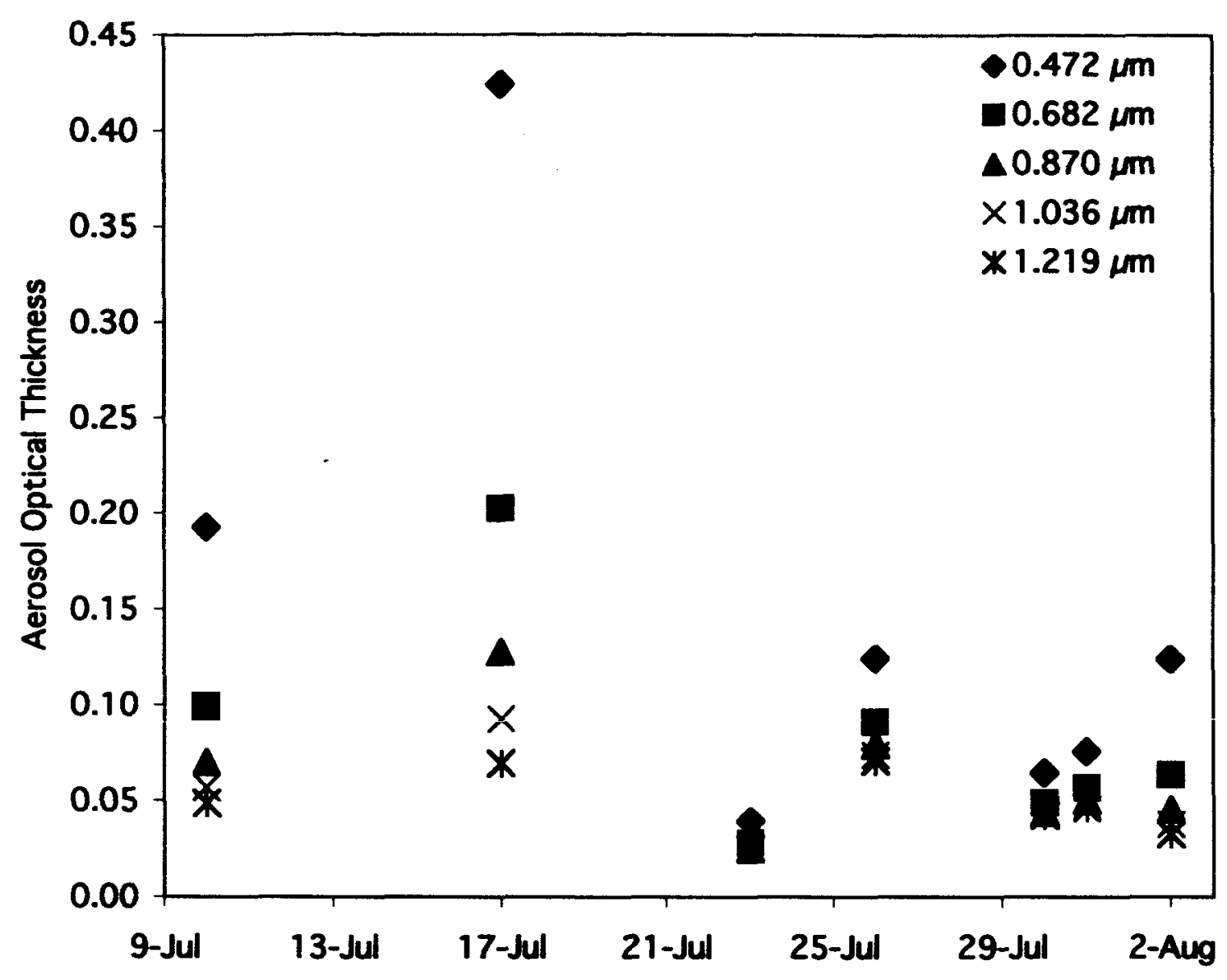

Figure 5. Variation of $\tau_{\mathbf{a}}$ aircraft $(\lambda)$ as measured by Ames Airborne Tracking Sunphotometer (AATS) during the CLAMS field experiment campaign at the time of BRDF measurements. 

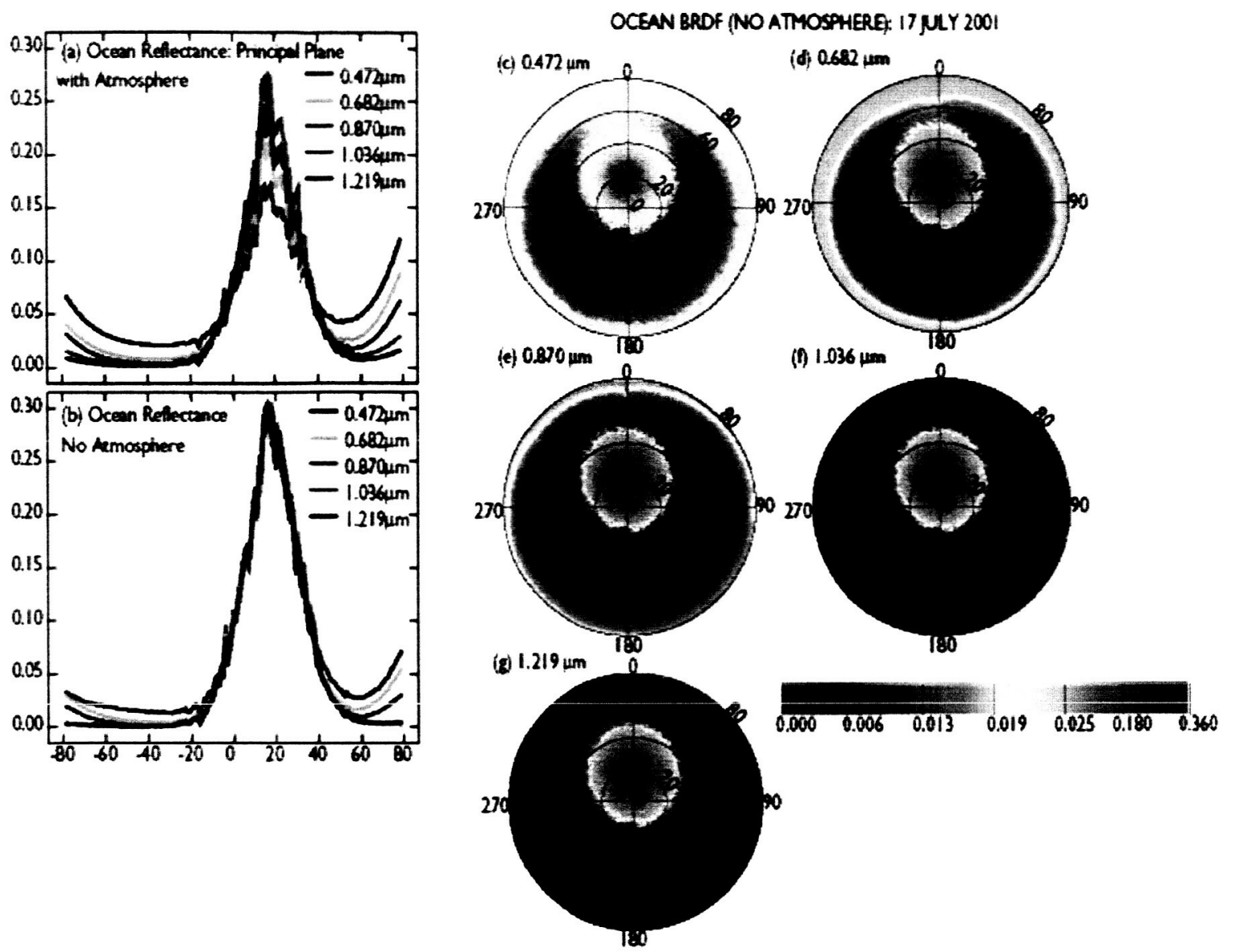

Figure 6. Illustration of atmospheric correction. Panels (a) and (b) show the angular distribution of bidirectional reflectance in the principal plane for measurements taken on 17 July 2001 at $\left(36.96^{\circ} \mathrm{N}, 75.72^{\circ} \mathrm{W}\right)$ in the vicinity of Chesapeake Light $\left(36.91^{\circ} \mathrm{N}, 75.71^{\circ} \mathrm{W}\right)$ before and after atmospheric correction. Panels (c) through (g) show the full atmospherically corrected BRDF for five CAR spectral channels in the visible and near-infrared. The broad reflectance peak represent the sunglint for an average solar zenith angle $\theta_{0}=16.23^{\circ}$. 

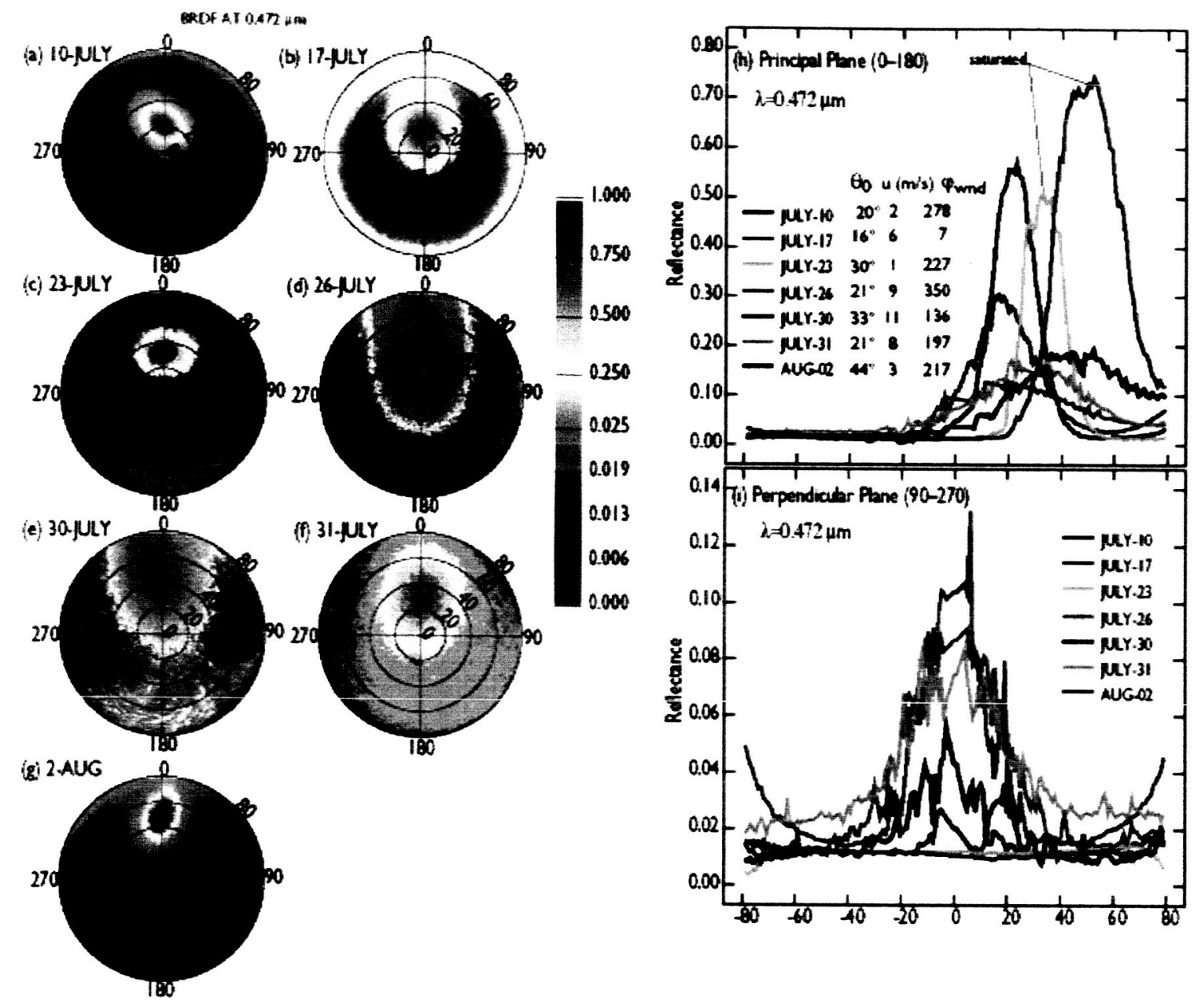

Figure 7. Spectral BRDF at $0.472 \mu \mathrm{m}$ for seven cloud-free cases obtained by CAR between 10 July and 2 August 2001 during CLAMS. The transects through and perpendicular to the plane of the Sun are also given. The effect of different illumination and wind conditions on the intensity, size, orientation, and location of sunglint are clearly seen. 

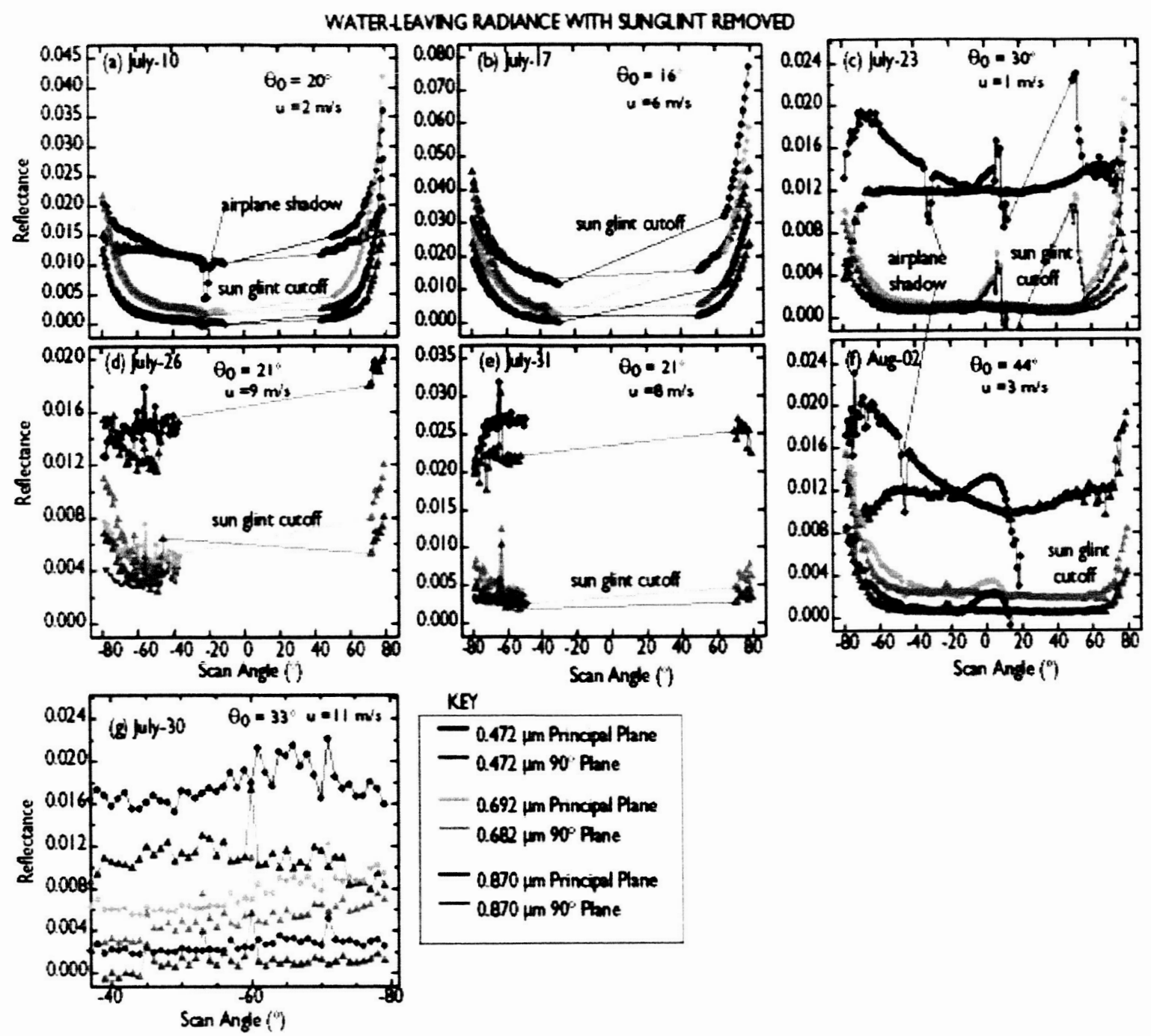

Figure 8. Water-leaving BRDF in the principal and perpendicular plane of the Sun at three CAR channels $(0.472,0.682$, and $0.870 \mu \mathrm{m})$ for seven cloud-free cases with various conditions. On average, even though the illumination conditions are different, water-leaving BRDFs do not seem to vary much from case to case. Note that 31 July measurements were obtained in deep Ocean unlike the other cases where measurements were obtained in the proximity of the coastline. The sunglint has been cutoff so as to be able to amplify the low varying BRDFs. 
(a) July -26: Low Gint RiMeasured - Cox-Munk) $\propto 0.472 \mathrm{~mm}$

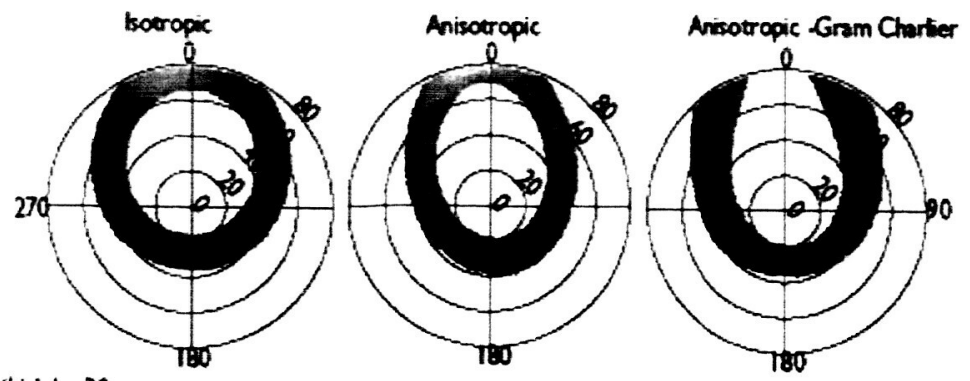

(bi) ply - 30.

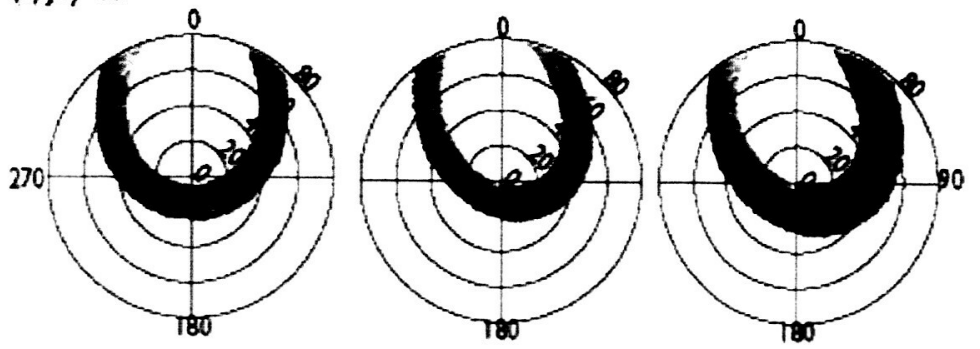

(c) July -31:
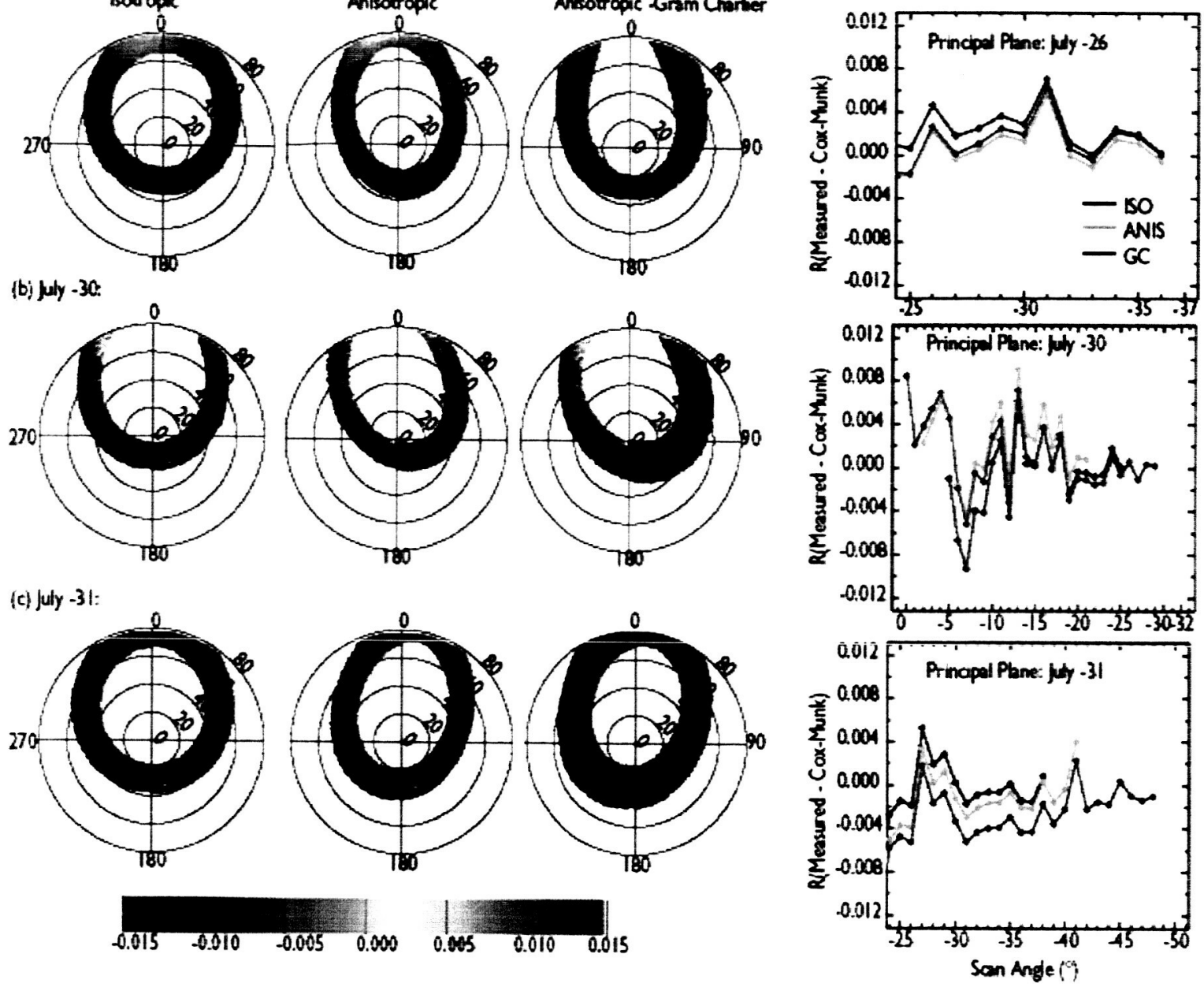

Figure 12. Differences between measurements and computed reflectance using isotropic Cox-Munk, and anisotropic Cox-Munk without and with Gram-Charlier expansion in the darkest part of the sunglint reflectance $(0.001<R<0.02)$. 


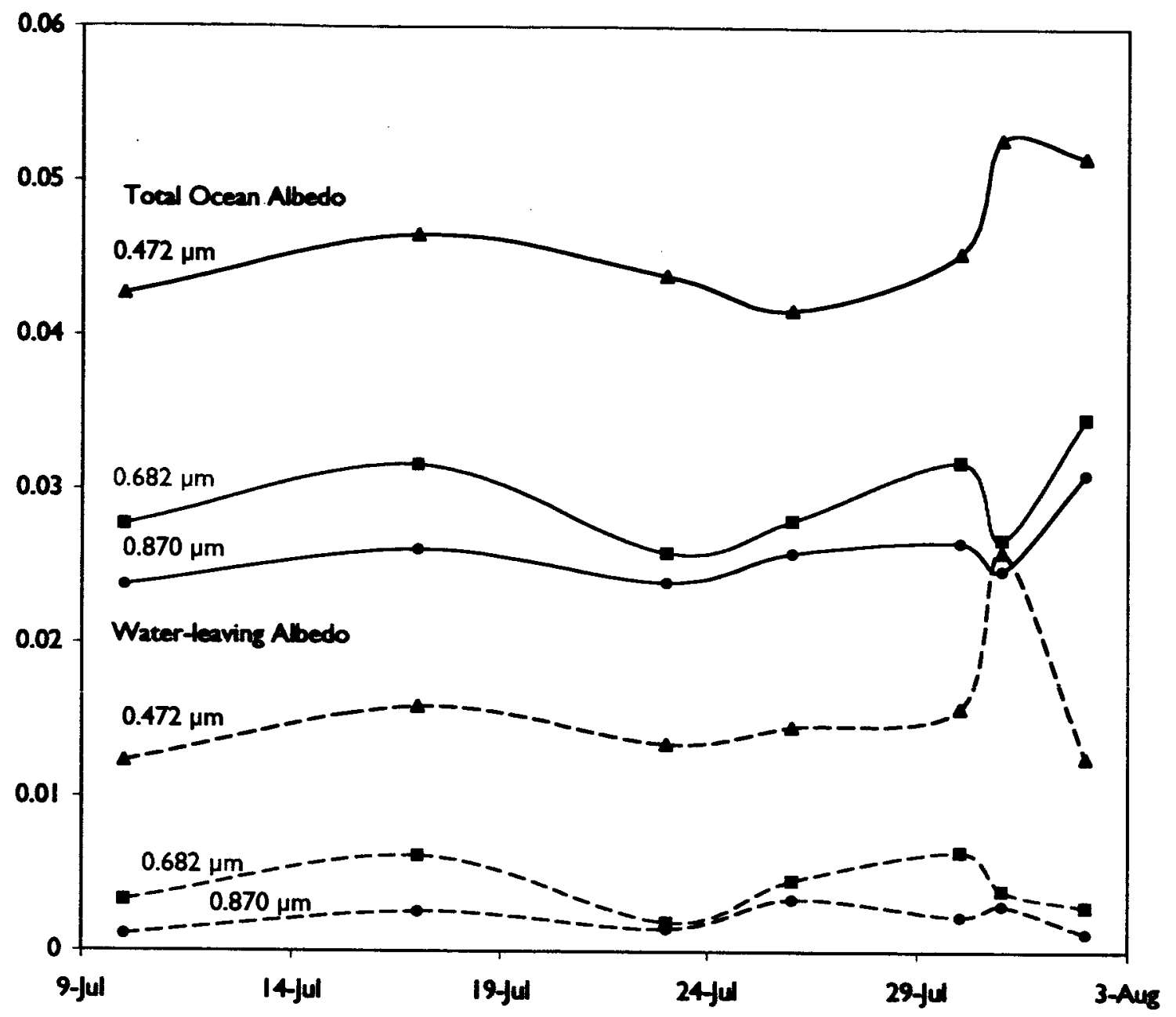

Figure 10. Total Ocean spectral albedo and average water-leaving (total albedo excluding the sunglint) for seven cloud-free cases of CAR measurements over the Atlantic off the U.S. east coast during the CLAMS field experiment campaign from $10 \mathrm{July}-2$ August 2001. 

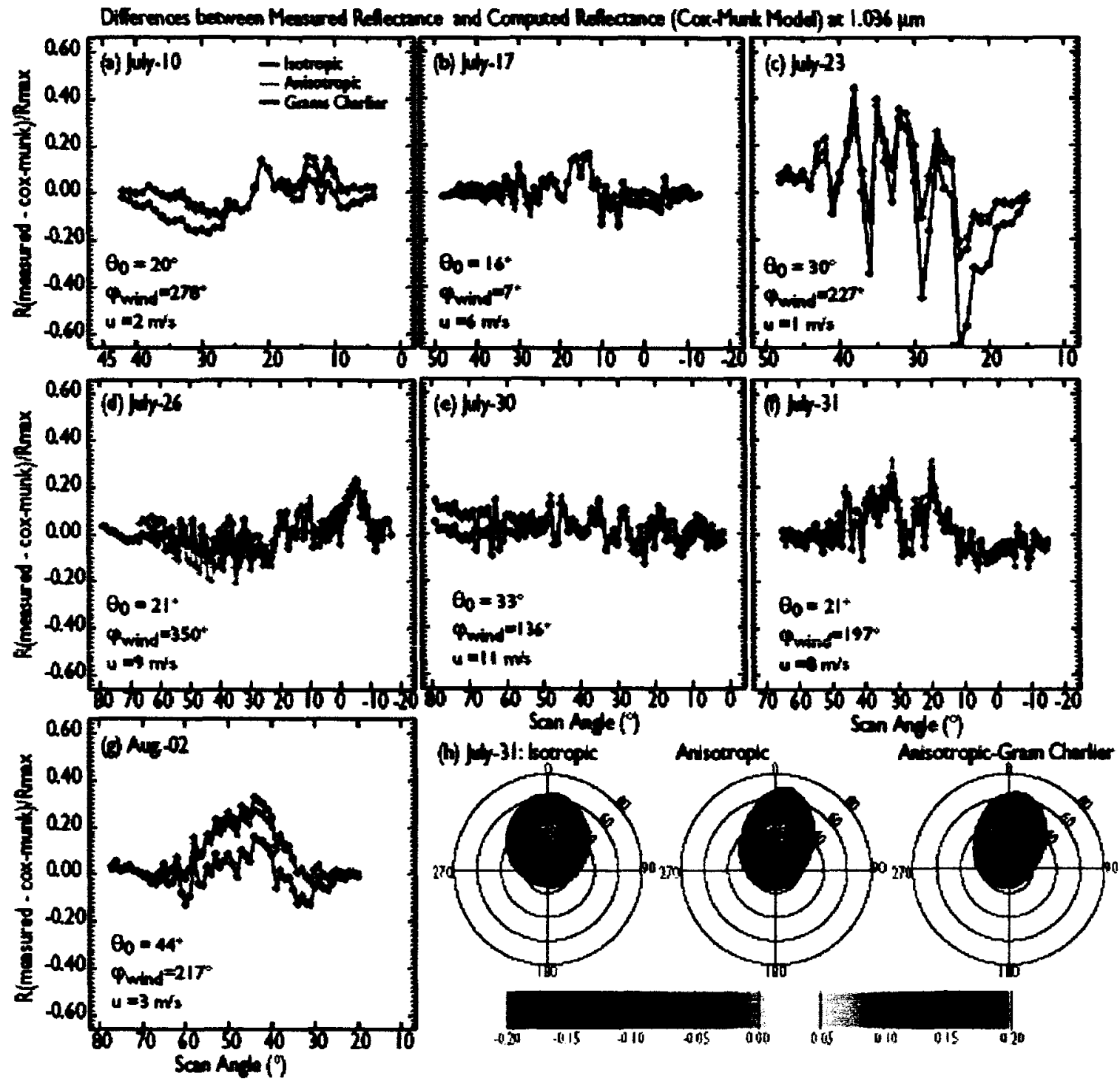

Figure 11. Normalized differences between measurements and computed reflectance using isotropic Cox-Munk, and anisotropic Cox-Munk without and with Gram Charlier expansion ( $a$ to $g$ ) for the brightest part of the sunglint where computed reflectance $R>0.02$. (h) shows the differences for the entire high glint region for 31 July, to serve as an illustration for the other cases. 


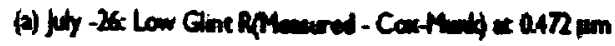

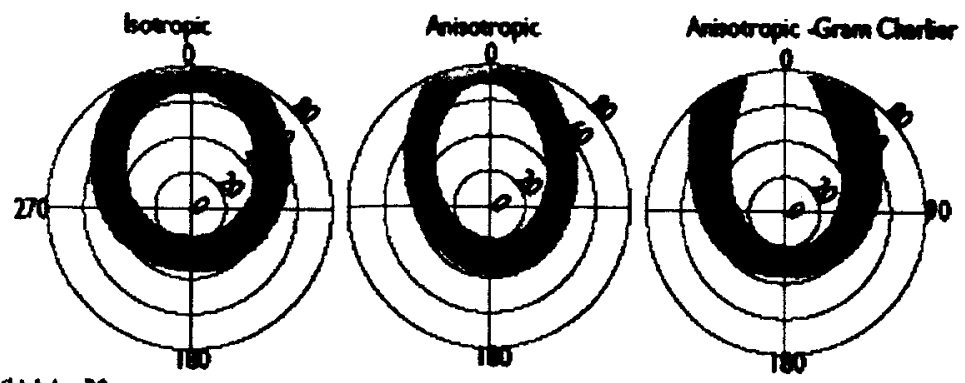

(b) $)$ ty $-3 x$

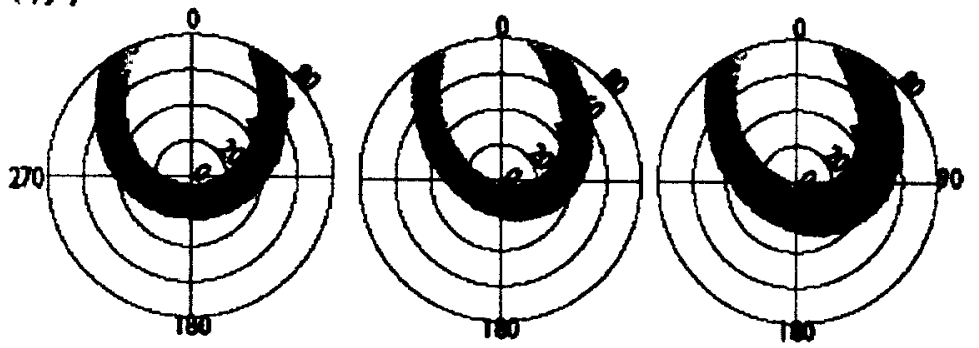

(c) july -31:
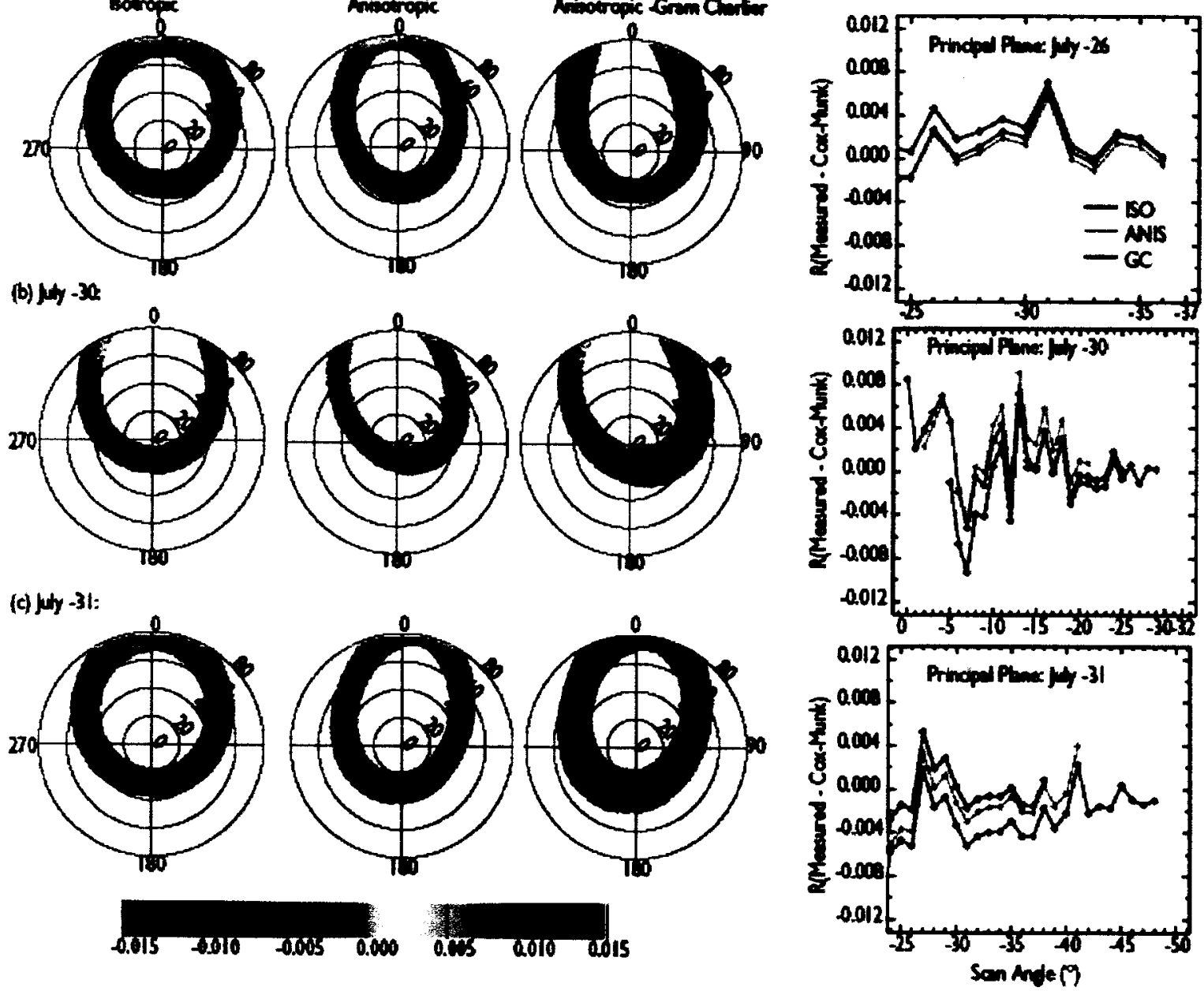

Figure 12. Differences between measurements and computed reflectance using isotropic Cox-Munk, and anisotropic Cox-Munk without and with Gram-Charlier expansion in the darkest part of the sunglint reflectance $(0.001<R<0.02)$. 

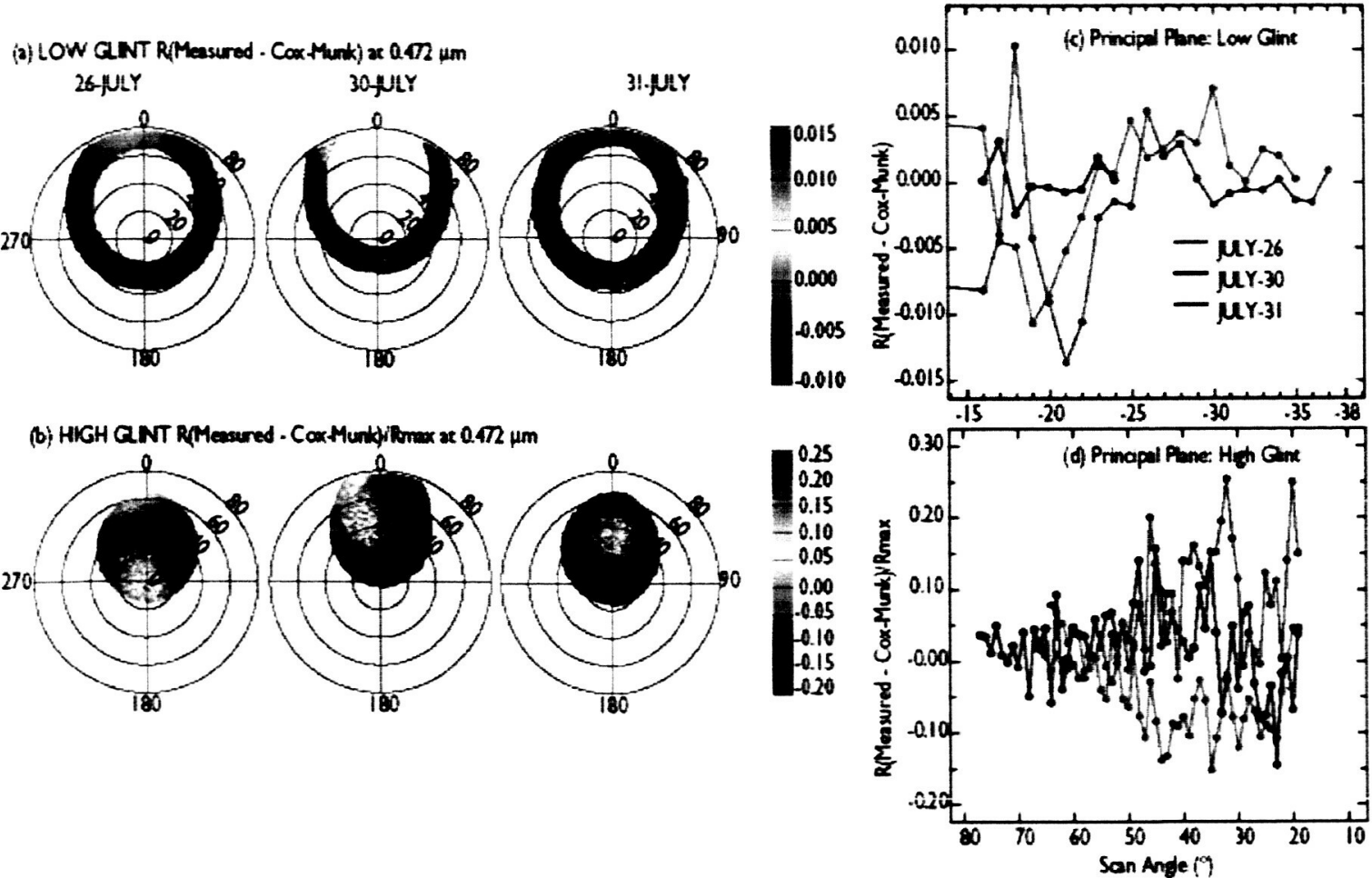

Figure 13. Comparison of differences between measurements and computed reflectance using anisotropic Cox-Munk with Gram Charlier expansion for both high glint and low glint for the three cases with the strongest wind (8-11 $\left.\mathrm{ms}^{-1}\right)$. 